NBER WORKING PAPER SERIES

\title{
A THEORY OF PYRAMIDAL OWNERSHIP AND FAMILY BUSINESS GROUPS
}

\author{
Heitor Almeida \\ Daniel Wolfenzon \\ Working Paper 11368 \\ http://www.nber.org/papers/w11368
}

\author{
NATIONAL BUREAU OF ECONOMIC RESEARCH \\ 1050 Massachusetts Avenue \\ Cambridge, MA 02138 \\ May 2005
}

Heitor Almeida and Daniel Wolfenzon are at the Stern School of Business, New York University and the National Bureau of Economic Research. We thank two anonymous referees, Ken Ayotte, Bernie Black, Mike Burkart, Luis Cabral, Mara Faccio, Rachel Hayes, Oliver Hart, Jay Hartzell, Rafael La Porta, Walter Novaes, Andrei Shleifer, Sheridan Titman, and seminar participants at the 2004 WFA meetings, the 2004 Corporate Governance Conference at the University of Texas, the 2004 UNC-Duke Conference on Corporate Finance, MIT, Princeton University, University of Minnesota, Tilburg University, the London Business School, the NYU/Columbia joint seminar, PUC-Rio, the University of Amsterdam, the Stockholm School of Economics, and the University of California San Diego for valuable comments. The usual disclaimer applies. The views expressed herein are those of the author(s) and do not necessarily reflect the views of the National Bureau of Economic Research.

(C2005 by Heitor Almeida and Daniel Wolfenzon. All rights reserved. Short sections of text, not to exceed two paragraphs, may be quoted without explicit permission provided that full credit, including $\odot$ notice, is given to the source. 
A Theory of Pyramidal Ownership and Family Business Groups

Heitor Almeida and Daniel Wolfenzon

NBER Working Paper No. 11368

May 2005

JEL No. G32

\begin{abstract}
$\underline{\text { ABSTRACT }}$
We provide a rationale for pyramidal ownership (the control of a firm through a chain of ownership relations) that departs from the traditional argument that pyramids arise to separate cash flow from voting rights. With a pyramidal structure, a family uses a firm it already controls to set up a new firm. This structure allows the family to 1) access the entire stock of retained earnings of the original firm, and 2) to share the new firm's non-diverted payoff with minority shareholders of the original firm. Thus, pyramids are attractive if external funds are costlier than internal funds, and if the family is expected to divert a large fraction of the new firm's payoff; conditions that hold in an environment with poor investor protection. The model can differentiate between pyramids and dual-class shares even in situations in which the same deviation from one share-one vote can be achieved with either method. Unlike the traditional argument, our model is consistent with recent empirical evidence that some pyramidal firms are associated with small deviations between ownership and control. We also analyze the creation of business groups (a collection of multiple firms under the control of a single family) and find that, when they arise, they are likely to adopt a pyramidal ownership structure. Other predictions of the model are consistent with systematic and anecdotal evidence on pyramidal business groups.

Heitor Almeida

NYU Stern School of Business

Department of Finance

44 West 4th Street, Room 9-85

New York, NY 10012

and NBER

halmeida@stern.nyu.edu

Daniel Wolfenzon

NYU Stern School of Business

Department of Finance

44 West 4th Street, Room 9-190

New York, NY 10012

and NBER

dwolfenz@stern.nyu.edu
\end{abstract}


Many firms in the world have a controlling shareholder, usually a family or the State (La Porta, Lopez-de-Silanes and Shleifer, 1999). In several countries, single individuals or families control a large number of firms; an organization typically referred to as a family business group. ${ }^{1}$ The controlling family often organizes the ownership of the group member firms in a pyramidal structure. $^{2}$ In such a structure the family achieves control of the constituent firms by a chain of ownership relations: the family directly controls a firm, which in turn controls another firm, which might itself control other firms, and so forth.

Despite the ubiquity of pyramidal business groups, there is surprisingly no formal theory that explains their existence. There are, however, some informal arguments. The traditional one is that a pyramid allows a family to achieve control of a firm with a small cash flow stake. ${ }^{3}$ For instance, a family that directly owns $50 \%$ of a firm, which in turn owns $50 \%$ of a different firm, achieves control of the latter firm with an ultimate cash flow stake of only $25 \%$. Securing control through such arrangements is beneficial for the family when private benefits of control are large. Because this view suggests that pyramids are created to separate cash flow from voting rights, it predicts that pyramidal firms should always be associated with a substantial separation between ownership and control. In fact, there are a number of examples in the literature in which firms in pyramidal groups are characterized by considerable separation between ownership and control (see for example Claessens, Djankov and Lang, 2000).

Nevertheless, a more detailed examination of the available data reveals some facts that cannot be adequately explained by the traditional view. For example, the finding that pyramidal firms are associated with large deviations from one share-one vote is not universal. There are many cases in which the separation achieved is minimal and does not seem to warrant the use of a pyramid (see, for example, Franks and Mayer, 2001, and section 4 for a discussion of this and other evidence).

\footnotetext{
${ }^{1}$ The term business group is sometimes used in the literature to refer to other types of corporate groupings such as those in which the member firms are tied together by common ethnicity of the owners, interlocking directorates, school ties, etc. An example is the Japanese keiretsu, an organization in which individual managers have considerable autonomy in their firms but coordinate their activities through the President Council and a common Main Bank (Hoshi and Kashyap, 2001). Another example are the horizontal financial-industrial groups in Russia (Perotti and Gelfer, 2001, p. 1604). To avoid confusion, we use the term family business groups to refer to groups in which member firms are controlled by the same family, such as the groups in Western Europe, Latin America, and East Asia.

${ }^{2}$ See, among others, Claessens, Djankov, and Lang (2000) for the evidence on East Asia, Faccio and Lang (2002) and Barca and Becht (2001) for Western Europe, Khanna (2000) for emerging markets, and Morck, Strangeland and Yeung (2000) for Canada.

${ }^{3}$ This argument goes back at least to the beginning of the 20th century. Berle and Means (1932) and Graham and Dodd (1934) use this argument to explain the creation of pyramids in the U.S. in the early 20th century.
} 
Moreover, even the cases in which pyramids do seem to separate cash flow from voting rights are not entirely explained by the traditional view. The reason is that pyramids are not the only way to achieve this separation. For example, absent restrictions to the use of dual-class shares, the family can achieve any degree of separation by directly owning the firm and selling shares with inferior or no voting rights. In such a case, why would a family choose to control a firm through a pyramid instead of using dual-class shares? Yet, despite this apparent equivalence, the empirical evidence indicates that pyramids are much more common throughout the world than dual-class shares (La Porta, Lopez-de-Silanes and Shleifer, 1999). The higher incidence of pyramids does not appear to be caused by restrictions to the use of dual-class shares. Although these restrictions set an effective upper bound to the deviation from one share one vote that can be achieved with dual-class shares, many pyramidal firms have deviations that fall below this permitted upper bound (Bianchi, Bianco and Enriques, 2001). All this evidence suggests that considerations other than separation of cash flow from voting rights motivate the creation of pyramidal business groups.

In this paper we present a model that provides a rationale for the existence of pyramids that does not rely on separation of cash flow from voting rights. The model is consistent with the finding that pyramids arise even in situations in which the family can use dual-class shares to facilitate control. The model can also explain why firms controlled through pyramids sometimes have substantial deviations between ownership and control, while other times the separation is minor. The theory addresses both the ownership structure of business groups (the reason why groups are organized as pyramids as opposed to a structure in which group firms are owned directly by the controlling family), and the existence of the group itself (the reason why a single family controls multiple independent firms). We show that the implications of the model are consistent with anecdotal and empirical evidence regarding the characteristics of pyramidal business groups.

The model has two key ingredients. The first one is the assumption of limited investor protection. If investor protection is poor, the family extracts private benefits from the firms it controls at the expense of minority shareholders. The second ingredient is the assumption that business groups are created over time. The family initially sets up a firm and, at some point in the future, the opportunity to set up another firm arises.

When this opportunity arises, the family must decide on the ownership structure of the business group. In a pyramidal structure the new firm is owned by all the shareholders of the original firm. 
As a result, the family shares the security benefits of the new firm with non-family shareholders of the existing firm, but it has access to the entire stock of retained earnings (cash) of the original firm. ${ }^{4}$ We consider an alternative ownership structure in which the family controls the new firm by directly holding its shares. We refer to this direct ownership structure as a horizontal structure. ${ }^{5}$ Under this structure, non-family shareholders of the existing firm have no rights to the cash flows of the new firm, and thus the family captures the entire security benefits of the new firm. However, the family only has access to its share of the retained earnings of the original firm. ${ }^{6}$

The level of investor protection plays a crucial role in the choice of structure. Poor investor protection leads to high diversion of cash flows, which makes the pyramidal structure more attractive for two reasons. First, diversion increases the family's private benefits of control, at the expense of a reduction in security benefits. ${ }^{7}$ Because in a pyramidal structure the family shares the security benefits with non-family shareholders, while in the horizontal structure it keeps them entirely, high diversion increases the family's payoff under the pyramidal structure relative to the payoff under the horizontal structure (payoff advantage). Second, because external investors anticipate diversion and discount the terms at which they are willing to provide finance, it is optimal for the controlling shareholders to use internal funds of existing firms to set up new firms, before any external finance is raised. ${ }^{8}$ Thus, the family's ability to use the entire stock of retained earnings of existing group firms when it chooses the pyramid becomes more valuable (financing advantage).

In addition to the level of investor protection, certain firm characteristics influence the choice of structure. In particular, we show that firms with high investment requirements and/or low profitability are more likely to be set up in pyramids. The argument is similar to that described in the previous paragraph. Because of their characteristics, these types of firms generate lower security benefits for investors. Thus, the family achieves a higher payoff and, at the same time,

\footnotetext{
${ }^{4}$ Security benefits represent the fraction of the firm's returns that is not diverted by the family and thus accrues to all shareholders. The remaining part (the diverted value) represents a private benefit of control for the family.

${ }^{5}$ Admittedly, we are analyzing two highly stylized ownership structures. In reality, business groups are more complex. However, by analyzing cleanly defined ownership structures, we hope to provide a starting point for the analysis of more complex groups.

${ }^{6}$ Graham and Dodd (1934) argue that the ability to use the resources of an already established firm to set up or acquire new firms was one of the reasons for the existence of pyramids in the U.S. in the early 1900's (see p. 564).

${ }^{7}$ There is a large empirical literature providing evidence that private benefits of control are larger in poor investor protection countries. See Zingales (1994), Nenova (1999) and Dyck and Zingales (2004).

${ }^{8}$ This argument is related to the pecking order theory of external finance (Myers and Majluf, 1984). However, the wedge between external and internal finance in our model arises from a moral hazard type of problem, and not from asymmetric information about firm cash flows.
} 
finds it easier to finance these firms if it uses a pyramid to set them up.

In sum, in our model pyramids are chosen by the family because of the payoff and financing advantages they provide when firms are expected to yield low security benefits relative to the required investments. This rationale for pyramids is different from that proposed by the traditional view. In particular, in our model pyramids can be optimal even if the opportunities for separating cash flow and votes with dual-class shares are not exhausted. This result helps explain one of the puzzles raised above.

In this paper we distinguish between a business group (a collection of firms controlled by the same family) and a pyramidal or horizontal structure (the particular ownership structure used to control the group's member firms). The analysis above assumes that the family always sets up the original and the new firm. However, we also analyze the conditions that allow the same family that set up the original firm to control the new firm. That is, we analyze the conditions that lead to the creation of a business group. As it turns out, these conditions are similar to those that are conducive to the creation of pyramids. A firm is more likely to be added to a business group when its security benefits are low relative to the required investments. In such cases, it is difficult for an outside, less wealthy entrepreneur to finance the required investment in the external market. As a result, families that already own successful firms might be the only ones with the financial resources to set up the new firm, regardless of whether they are the most efficient owners. Thus, business groups should be more prevalent in poor investor protection countries and they should adopt a pyramidal structure. This implication is consistent with available empirical and anecdotal evidence (e.g., La Porta, Lopez-de-Silanes and Shleifer, 1999).

The observation that pyramidal firms are associated with low security benefits raises another question. Because the low security benefits are shared with existing shareholders of the business group, these shareholders might not find it optimal to buy into the business group in the first place. To answer this question, we analyze the set up of the first firm in the business group and show that pyramids can still arise. First, if the family cannot contractually commit to rule out pyramids in the future, it simply compensates shareholders for the future costs of pyramiding by transferring a large enough fraction of the value of the first firm to them (through a reduced share price). Second, the family might not want to commit to rule out pyramids. Because retained earnings relax financing constraints, and because in a pyramidal structure the family has access to a greater 
pool of internal funds, there are situations in which the family needs to use pyramids to add new firms to the group. Thus, contractual mechanisms to rule out pyramids might not be used even if it is feasible to enforce them.

We also show that observed ultimate ownership is lower and equilibrium diversion is higher in firms that are controlled through pyramids. This result is driven by a selection effect. Firms with low security benefits relative to their investments require that the family sell more shares to finance them. As a result, the family's ultimate stake in these firms is low, and diversion high. But, as explained above, given that expected diversion is high, it is optimal for the family to set these firms up in a pyramidal structure. Thus, firms with low security benefits relative to their investment requirements are associated with lower ownership concentration, high diversion and end up in pyramidal structures. Similarly, firms with high security benefits relative to their investment requirements are associated with high ultimate ownership concentration, low diversion and are more likely to be set up in horizontal structures, or even outside business groups. This prediction is consistent with evidence that shows significant expropriation of investors in firms that belong to pyramidal structures (Bertrand, Mehta and Mullainathan, 2002, and Johnson et al., 2000). However, it is important to point out that, in our model, the pyramidal structure itself is not the cause for the increased diversion. Rather, the expectation of high levels of diversion makes the pyramidal structure an optimal choice for the controlling family.

Despite the fact that pyramidal firms are associated with lower ultimate ownership relative to firms controlled directly by the family, our model does not necessarily require (as the traditional argument does) that the ultimate ownership concentration in a pyramidal firm be small in an absolute sense. ${ }^{9}$ In fact, our model is consistent with families holding either large or small ultimate ownership stakes in pyramidal firms, leading to either minor or substantial separation of cash flow from voting rights. This result helps explain another of the puzzles raised above, namely, that pyramidal structures with small deviation between cash flow and votes do exist. In addition, we show that pyramidal structures with small deviations are more likely to appear in poor investor protection countries.

Finally, we consider extensions of the basic model that address additional questions raised by

\footnotetext{
${ }^{9}$ The selection argument above only suggests that families should hold smaller ownership stakes in firms that they control through pyramids, relative to firms that they own directly. This prediction is not incompatible with high observed ownership stakes in pyramidal firms, in an absolute sense.
} 
the theory. First, we analyze whether it is optimal for the family to set up new firms as legally independent entities or as divisions inside existing firms. This question is important because, if new firms are set up as divisions, the resulting structure does not match the usual definition of a pyramid. Within the framework of our model, we show that as long as there is variation in the level of investor protection across firms in the same group, the family is very likely to set up the new firm as a partial subsidiary.

Second, we extend the model to allow for a variable scale of investment in firm B. We show that our previous conclusions are robust to this natural extension. We also show that the family might have an incentive to overinvest in firms that are owned through pyramids, because the cost of overinvestment is shared with existing shareholders of the business group. Such overinvestment is more likely when retained earnings in the business group are very large. Thus, the possibility of pyramiding might destroy value if there is too much cash available to the family, a version of the well-known free cash flow problem (Jensen, 1986).

Existing literature treats the creation of business groups and the determinants of their ownership structures separately. Regarding business groups, Leff (1978) and, more recently Khanna and Palepu (1997, 1999), argue that they arise to substitute for missing markets (e.g. labor and financial markets). ${ }^{10}$. Other benefits of groups include the possibility to prop up (inject money into) failing firms (Morck and Nakamura, 1999, Friedman, Johnson, and Mitton, 2003) and the use of a group's deep pockets as a strategic tool in product market competition (Cestone and Fumagalli, 2004). None of these arguments considers the ownership structure (e.g., pyramids, horizontal structure, etc.) of the business group.

To explain the ownership structure of groups, the literature has relied on a different set of arguments. As we discussed above, the traditional argument for pyramids is that they arise to separate cash flow from voting rights. The question still remains as to why a pyramid is the best mechanism to achieve this separation. The same observation can be made regarding the models in Gomes (2000), who shows that separation of cash flow and voting rights might have reputation benefits, and Bebchuk (1999), who argues that an initial owner might want to separate cash flow and voting rights to prevent potential raiders from seizing valuable control. Regulatory or tax considerations might also help explain the existence of pyramids. For example, Morck (2003)

\footnotetext{
${ }^{10}$ See also Aoki (1984), Ghatak and Kali (2001), and Kim (2004) for other value-enhancing arguments.
} 
shows evidence that taxes on inter-company dividends affect the incidence of pyramidal structures.

Our basic model of pyramidal and horizontal business groups is presented in section 1 . We initially consider a version of the model in which the family already owns a given firm, and needs to decide on the structure to use (pyramidal or horizontal) to set up a new firm. We use this framework to characterize the conditions that lead to the choice of each structure by the family. Next, we consider the creation of business groups. We end this section by analyzing the creation of the first firm in the group. In section 1 we assume that diversion entails no costs. This assumption makes diversion insensitive to the firm's ownership structure, and simplifies the analysis considerably. In section 2 we relax this assumption, and derive implications regarding variations in diversion and ownership concentration in different structures. Section 3 considers the question of whether new projects that are taken by the pyramid should be organized as stand-alone firms or divisions, and the implications of a variable scale of investment in the new firm. Our theory generates a number of empirical implications that we discuss in section 4 together with the relevant empirical literature. Section 5 concludes.

\section{Pyramidal and horizontal business groups}

In this section we present a framework to analyze pyramidal and horizontal business groups. The model has three dates. At date 0, a family sets up a firm (firm A), keeping a fraction $\alpha$ of its shares. At date 1, firm A generates cash flows of $c$, and the opportunity to set up another firm (firm B) arises. Firm B requires an investment $i$ at date 1 and generates a revenue $r$ at date 2, with $r>i$. We also assume for now that the family is the only possible owner of firm $\mathrm{B}$. In section 1.4 we analyze the effects of competition from an alternative owner.

At date 1, the family chooses the optimal ownership structure for firm B (horizontal or pyramidal). In a pyramidal structure, the family sets up firm B as a partial subsidiary of firm A and thus can use the cash $c$ in firm A to set up firm B. In an horizontal structure, the family itself -and independently from firm A- sets up firm B. In this case, the family has access only to its personal wealth of $\alpha c$. In either structure, the family sells shares of firm B to raise additional funds.

We assume that there are no legal restrictions to the use of dual-class shares. This assumption

ensures that the family always retains complete control of firm $\mathrm{B}$, irrespective of the structure it chooses and its ultimate ownership. 
Control allows the family to divert cash from firm B into its pockets. We assume that when the family diverts $d r$ of the cash flows, it pays a cost (one can think of this as waste involved in the diversion process) of $c(d, k) r$, where $k$ is the level of investor protection.

One implicit assumption in this formulation is that diversion opportunities are the same regardless of the structure the family chooses. The reason for this assumption is that, because the family retains the same degree of control in both structures, the set of feasible actions the family can take and hence the diversion opportunities should be the same. Of course, as we will see below, actual diversion will be affected by the incentives that the family faces in each structure. Finally, notice that our diversion technology does not capture intra-firm diversion (e.g., diversion from firm B to firm A) or diversion directly from firm A. However, our results continue to hold if we allow for these different diversion opportunities. ${ }^{11}$

Finally, we assume that the market interest rate is zero and that the family maximizes its date 2 payoff. We start by solving the model from date 1 and take the family stake in firm A, $\alpha$, as given. In section 1.5, we endogenize $\alpha$ by solving the model from date 0 .

\subsection{Horizontal structure}

The family has personal wealth of $\alpha c$. To set up firm B at date 1 , the family contributes $R_{I}^{H}$ of these funds and raises $R_{E}^{H}$ from the external market by selling $1-\beta^{H}$ shares of firm B (the subscripts $I$ and $E$ stand for internal and external funds, respectively). The family's payoff at date 2 can be written as

$$
\alpha c-R_{I}^{H}+\beta^{H}\left(R_{I}^{H}+R_{E}^{H}-i+(1-d) r\right)+(d-c(d, k)) r .
$$

At date 2, the family chooses the level of diversion that maximizes the above expression. Thus, $d=\arg \max _{d} \beta^{H}(1-d)+d-c(d, k)$. This expression defines $d\left(\beta^{H}, k\right)$.

Because investors break even in equilibrium, we can write $R_{E}^{H}=\left(1-\beta^{H}\right)\left(R_{I}^{H}+R_{E}^{H}-i+(1-d) r\right)$. Solving this equation for $R_{E}^{H}$, plugging this value into Equation (1), and letting $N P V \equiv r-i-$ $c(d, k) r$ be the NPV of firm B net of diversion costs, we obtain the payoff of the family as of date 1:

$$
U^{H}=\alpha c+N P V
$$

\footnotetext{
${ }^{11}$ We analyzed these alternative diversion opportunities in a previous version of the paper (available from the authors upon request).
} 
This expression is the family's payoff conditional on firm B being set up. The family is able to set up firm B whenever $R_{I}^{H}+R_{E}^{H} \geq i$, which by replacing the value for $R_{E}^{H}$ leads to

$$
R^{H} \equiv R_{I}^{H}+\left(1-\beta^{H}\right)(1-d) r \geq i
$$

Conditional on setting up firm B, the family's date 1 problem is:

$$
\begin{gathered}
\max _{R_{I}^{H} \in[0, \alpha c], \beta^{H} \in[0,1]} U^{H} \\
\text { subject to } R^{H} \geq i \\
\text { and to } d=d\left(\beta^{H}, k\right) .
\end{gathered}
$$

\subsection{Pyramidal structure}

Firm A has retained earnings of $c$, out of which it contributes $R_{I}^{P}$ to the set up cost of firm B. In addition, it raises $R_{E}^{P}$ from the external market by selling $1-\beta^{P}$ shares of firm B. The family's payoff at date 2 is given by

$$
\alpha\left[c-R_{I}^{P}+\beta^{P}\left(R_{I}^{P}+R_{E}^{P}-i+(1-d) r\right)\right]+(d-c(d, k)) r
$$

where $R_{I}^{P}+R_{E}^{P}-i+(1-d) r$ are the security benefits of firm B at date 2 .

At date 2, the family chooses the level of diversion that maximizes the above expression. Thus, $d=\arg \max _{d} \alpha \beta^{P}(1-d)+d-c(d, k)$. Comparing this expression with the corresponding one in the horizontal case, it can be seen that in both structures diversion depends in the same way on ultimate ownership ( $\beta^{H}$ in the horizontal structure and $\alpha \beta^{P}$ in the pyramidal). Therefore, diversion in the pyramidal case is given by $d\left(\alpha \beta^{P}, k\right)$. In section 2 , it will be more convenient to think about the family as choosing its ultimate ownership concentration in firm B rather than the direct ownership. Thus, for future reference we define $\omega^{H} \equiv \beta^{H}$ and $\omega^{P} \equiv \alpha \beta^{P}$.

Moving back to date 1 , we write $R_{E}^{P}=\left(1-\beta^{P}\right)\left(R_{I}^{P}+R_{E}^{P}-i+(1-d) r\right)$. Solving for $R_{E}$ and plugging this expression into Equation (5), we get the family's payoff as of date 1:

$$
U^{P}=\alpha c+N P V-(1-\alpha)[(1-d) r-i]
$$

The payoff differences between the horizontal and the pyramidal structures can be derived by comparing Equations (2) and (6). In the horizontal structure the family sets up firm B and, because new investors of firm B break even, the family ends up capturing the entire NPV of the 
project. In the pyramidal structure firm A sets up firm B, and so the NPV is shared between the family and non-family shareholders of firm A. However, the NPV is not distributed in proportion to the stakes in firm A because the family -but not the other shareholders of firm A- receives the diverted amount. Only the non-diverted NPV $((1-d) r-i)$ is divided in proportion to the stakes in firm A. That is, non-family shareholders of firm A get $(1-\alpha)[(1-d) r-i]$ and the family receives the rest.

For the family to be able to set up firm $\mathrm{B}$, it must be that $R_{I}^{P}+R_{E}^{P} \geq i$. Replacing the value of $R_{E}^{P}$ leads to

$$
R^{P} \equiv R_{I}^{P}+\left(1-\beta^{P}\right)(1-d) r \geq i
$$

The family's problem conditional on setting up firm B is

$$
\begin{aligned}
& \max _{R_{I}^{P} \in[0, c], \beta^{P} \in[0,1]} U^{P} \\
& \text { subject to } R^{P} \geq i \\
& \text { and to } d=d\left(\alpha \beta_{P}, k\right) .
\end{aligned}
$$

\subsection{Choice of structure, investor protection and firm characteristics}

There are two parts to the family's problem. First, the family finds the optimal ownership concentration for each of the two possible structures (problems in Equations (4) and (8)). Next, it chooses the structure that provides the highest payoff.

To provide the intuition for each of the two steps, we first consider a very simple cost of diversion function that guarantees that, in equilibrium, the cost of diversion is always zero. We show that this simplifying assumption implies that the family's payoff is independent of ownership concentration. This allows us to abstract from the effects of ownership concentration and isolate the choice of structure.

In section 2 we allow diversion to be costly, using a similar framework to that in Burkart, Gromb, and Panunzi (1998), and Shleifer and Wolfenzon (2002). With this assumption, diversion, the cost of diversion, and consequently the family's payoff depend on ultimate ownership concentration. This new assumption allows us to derive additional implications regarding the optimal ownership concentration and equilibrium levels of diversion, but it does not change the substance of the implications of the model of this section. 
We assume that diversion entails no cost and that the level of investor protection limits the amount of diversion that can take place (similar formulations of the diversion technology can be found in Pagano and Roell (1998) and in Burkart and Panunzi (2002)). In other words, we assume that:

$$
c(d, k)=\left\{\begin{array}{cc}
0 & \text { if } d \leq \bar{d}(k) \\
+\infty & \text { otherwise }
\end{array},\right.
$$

with $\frac{\partial \bar{d}}{\partial k}<0$.

Because diversion up to $\bar{d}$ is costless, the family sets $d=\bar{d}$, regardless of the structure it uses. Using Equations (2) and (6), we get

$$
\begin{aligned}
& U^{H}=\alpha c+N P V, \text { and } \\
& U^{P}=\alpha c+N P V-(1-\alpha)[(1-\bar{d}) r-i],
\end{aligned}
$$

where $N P V=r-i$. These payoffs, however, are conditional on the project being taken. Because payoffs are not affected by ownership concentration, the family is indifferent among all ownership concentration levels that allow it to raise the necessary funds. Therefore, without loss of generality, we assume that the family chooses the ownership concentration that allows it to raise the most funds.

In the case of the horizontal structure, we define:

$$
\bar{R}^{H} \equiv \max _{R_{I}^{H} \in[0, \alpha c], \beta^{H}} R^{H}=\alpha c+(1-\bar{d}) r
$$

The horizontal structure is feasible whenever $\bar{R}^{H} \geq i$. In this simplified model, because diversion does not depend on ownership concentration, the family maximizes the funds raised by fully dispersed ownership in firm B. This is not a general result. As we show in section 2, with costly diversion the family always tries to keep ownership concentration as high as possible.

Similarly, for the pyramidal case we define:

$$
\bar{R}^{P} \equiv \max _{R_{I}^{P} \in[0, c], \beta^{P}} R^{P}=c+(1-\bar{d}) r
$$

The pyramidal structure is feasible whenever $\bar{R}^{P} \geq i$. In this case, firm A contributes all of its retained earnings, $c$, and fully disperses ownership in firm B.

The following result characterizes the choice of structure in this version of the model. 
Result 1 If the non-diverted NPV of firm $B,(1-\bar{d}) r-i$, is positive, the family always chooses the horizontal structure. If the non-diverted NPV of firm B is negative and the pyramid is feasible $\left.\bar{R}^{P}>i\right)$, the family chooses the pyramid. In all other cases firm $B$ is not set up.

The proof of this result, as well as all other proofs, is in the appendix. When the non-diverted NPV is positive, firm B can be financed in either structure because the contribution of external investors, $(1-\bar{d}) r$, is sufficient to pay the investment cost, $i$. In terms of payoffs, however, the family prefers the horizontal structure. If the family sets up the pyramid, it shares this positive non-diverted NPV with the non-family shareholders of firm A, whereas if it chooses the horizontal structure it gets to keep the entire amount. Therefore, in this case, the horizontal structure is chosen.

When the non-diverted NPV is negative, firm B is not always feasible because the maximum amount external investors contribute is less than the set up costs. Firm B is feasible only when the internal resources are sufficiently high. In addition, when the non-diverted NPV is negative, the family prefers the pyramid because this structure allows it to share this negative value with the other shareholders of firm A. Therefore, in this region, the family chooses the pyramidal structure whenever it is feasible.

Result 2 Assume that $\bar{R}^{P} \geq i$, such that firm $B$ is feasible under the pyramidal structure. Given this condition, firm B is less likely to be owned through a pyramid when

- Firm B generates higher revenues

- Firm B requires a smaller investment

- Investor protection increases

This result follows from the fact that the non-diverted NPV is higher and so more likely to be positive when profitability increases, investment decreases or investor protection is stronger. Because the non-diverted NPV is more likely to be positive, the family is more likely to use a horizontal structure both because its payoff is higher, and because it becomes easier to finance the project. $^{12}$

\footnotetext{
${ }^{12}$ We condition on firm B being feasible under the pyramidal structure because, empirically, only the set of projects that are feasible under the least restrictive conditions is observable.
} 
Our assumption that there are no legal restrictions to the use of dual-class shares implies that the family can use either structure to secure control, regardless of how small a cash flow it holds. Therefore, in this framework any argument for the existence of pyramids that relies on separation of ownership and control (e.g., the traditional argument) cannot make predictions as to which structure the family should use. Because in our model pyramids are not used to separate ownership from control, but rather to allow the family to maximize its internal sources of financing and to share the security benefits of new firms, they can be optimal in this environment. That is, in our model, pyramids are not equivalent to direct ownership with the (potential) use of dual-class shares, even when there are no legal restrictions to the use of dual-class shares.

\subsection{Business groups}

We define a business group as an organization in which a family owns and controls more than one firm. In the last section we assumed that the family is the only party with the ability to set up firm B. This effectively means that we assumed the existence of a business group. In this section we investigate the conditions under which a business groups arises.

We introduce the possibility that, at date 1, there is an alternative owner for firm B (whom we call the entrepreneur). The set up cost of firm B for the entrepreneur is also $i$. The entrepreneur might be a better or a worse manager than the family, a possibility that we capture by assuming that under his control revenues of firm B are $(1+t) r$. The parameter $t$ can be positive or negative, and is a measure of the productivity differential between the family and the entrepreneur. We also assume that the entrepreneur has no personal wealth. Thus, if the parameter $t>0$, the only advantage of the family is its higher financing capacity due to the accumulation of internal funds in the existing firms it owns (that is, the cash $c$ of firm A).

For simplicity, we assume that the market in question only allows for one firm. ${ }^{13}$ Thus, if $t<0$ the family will be the natural owner of the firm because it has both a technological and a financing advantage. If $t>0$, the entrepreneur is the most productive owner but might not own the firm because of the family's wealth advantage. We capture this possibility by assuming that, if the entrepreneur can raise sufficient funds, he will be the only one to enter the market because of his

\footnotetext{
${ }^{13}$ Presumably, the family and the entrepreneur would engage in some form of competition for the market, which might involve a phase when both enter and attempt to capture the market. Our assumption that only one can enter can be seen as a reduced form of a competition game under which one of the firms must eventually prevail.
} 
higher productivity. If he cannot raise the necessary funds, then the family sets up firm B using any of the two structures described in the last section. ${ }^{14}$ Given this assumption, we can prove the following result.

Result 3 Business groups are less likely to arise when

- The entrepreneur's productivity differential, $t$, is positive and large

- Firm B generates higher revenues

- Firm B requires a smaller investment

- Investor protection is higher

If $t>0$, the comparative advantage of the family is that they have accumulated wealth, and thus do not need to rely as much on external capital markets. As investor protection improves, the comparative advantage of the family eventually disappears and the entrepreneur is able to set up his firm. The entrepreneur is also more likely to raise the necessary funds to set up firm B when firm B's NPV is large, which happens when $r$ and $t$ are high, and $i$ is low.

Notice that the conditions that are conducive to the formation of business groups are also conducive to the formation of pyramids (compare Results 2 and 3). In fact, in this simple model we can prove the following result.

Result 4 Business groups that arise because of the family's financing advantage, that is, when $t>0$, are always organized as pyramids. If $t<0$ it is possible that business groups are organized horizontally.

If $t>0$, competition from the entrepreneur eliminates the region of the parameter space in which a horizontal structure arises. Thus, in our model, there is an endogenously derived equivalence between business groups that arise due to financing reasons and pyramids. The intuition for this result is that horizontal structures only appear when the non-diverted NPV of firm B is positive,

\footnotetext{
${ }^{14}$ The assumption that a more productive entrepreneur owns the firm whenever he can finance it is a bit extreme. A situation could arise in which the wealthy family manages to drive out an entrepreneur that is only marginally viable, for example by using its financing clout to lower the output price. However, such a possibility would not lead to results that are qualitatively different than the ones we describe below, since it would still be the case that the entrepreneur would become the most natural owner if its productivity differential and/or firm B's security benefits are large enough. See also the proof of result 3.
} 
because in such cases the family does not want to share the positive NPV of firm B with the existing shareholders of firm A. However, under such conditions entrepreneurial finance is possible, because the fraction of the profits of firm B that can be pledged to outside investors, $(1-\bar{d})(1+t) r$, is bigger than the investment $i$. Thus, the situations in which an horizontal structure is optimal are precisely the situations in which the business group loses its financing advantage over the entrepreneur. This also means that horizontal groups can only arise because of technological reasons, that is, when $t<0$. Finally, notice that a corollary of result 4 is that conditional on the business group arising, a pyramid is more likely to appear when the family is not the most efficient owner of firm B.

It is worth discussing what is novel regarding the results in this section. The idea that business groups are more likely to arise in countries with poor investor protection because external financing is more limited is not new. This idea is related to the arguments in Leff (1978) and Khanna and Palepu (1997, 1999), mentioned in the introduction. However, these authors have not considered the optimal choice of ownership structure in a business group. Result 4 suggests that, if business groups are created to substitute for financial markets that are curtailed by poor investor protection, they should also be organized as pyramids.

\subsection{Ex-ante optimality of pyramids}

In our model, whenever the pyramidal structure is chosen shareholders of firm A realize a negative return, because they share the negative non-diverted NPV with the family. This raises the question of why shareholders buy into firm A in the first place. Even though it is possible that shareholders do not anticipate the creation of a pyramid, in this section we analyze a model in which shareholders rationally foresee this event..$^{15}$

To analyze this question, we extend the model to date 0 . We assume that, at date 0 , firm $\mathrm{A}$ needs an investment of $i_{A}$ and generates revenues of $r_{A}>i_{A}$ at date 1. Similarly, firm $\mathrm{B}$ requires an investment of $i_{B}$ at date 1 and generates a revenue of $r_{B}$ at date 2 . For simplicity, we assume that there is no diversion of the cash flows of firm A. We also assume that the family has no wealth at date 0 , and we do not consider competition by the entrepreneur, neither at date 0 , nor at date 1. ${ }^{16}$

\footnotetext{
${ }^{15}$ Aganin and Volpin (2005) document the case of the Pesenti group. The first firm in the group, Italcementi, was established in 1865. The creation of the Pesenti pyramid happened when the family started to acquire firms in 1945. The possibility that shareholders in 1865 foresaw the creation of a pyramid 80 years later, is possible, but unlikely.

${ }^{16}$ If competition at date 0 leads to the entrepreneur setting up firm A, then the entrepreneur becomes the family
} 
Suppose first that the family cannot commit at date 0 to rule out the use of pyramids in the future. In this case we have the following result.

Result 5 Suppose that $r_{A}+(1-\bar{d}) r_{B}>i_{A}+i_{B}$, and that $(1-\bar{d}) r_{B}<i_{B}$. In this case, the family sets up firm $A$ at date 0 and uses a pyramid to set up firm $B$ at date 1. Shareholders of firm $A$ break even from the perspective of date 0 .

The above result shows that, absent any contractual mechanisms to rule out pyramids, these structures can appear even when investors in the initial firm anticipate their formation. Intuitively, the first firm that the family sets up must be profitable enough in order to compensate initial shareholders for the future expropriation associated with pyramids. If this condition holds, the group's shares can be priced low enough such that initial shareholders break even and the family can raise enough to finance firm $\mathrm{A}$.

However, Result 5 does not rule out the possibility that the family might benefit from a mechanism (such as a contract or a charter provision) that allows it commit not to use pyramids. This commitment might be valuable because, from the perspective of date 0 , the family bears all costs of future expropriation associated with pyramids. ${ }^{17}$

Importantly, the family may not want to rule out pyramids by contract even if it can do so. There are cases in which the only way the family can set up both firms A and B is by allowing pyramidal structures. Ruling out pyramids might thus eliminate the possibility of setting up firm B. Since firm B is a positive NPV project, this is inefficient from an ex-ante perspective.

This type of situation arises when there is uncertainty regarding the cash flow produced by firm A. Suppose that the revenue generated by firm $\mathrm{A}$ is $r_{A}=\bar{r}_{A}-\Delta$ with probability $\frac{1}{2}$, and $r_{A}=$ $\bar{r}_{A}+\Delta$ with probability $\frac{1}{2}$.

Result 6 Suppose that the following conditions hold:

$$
\left(1-\frac{i_{A}}{\bar{r}_{A}}\right) \Delta+\bar{r}_{A}-i_{A}+(1-\bar{d}) r_{B}-i_{B}<0,
$$

in date 1, from the perspective of our model. Competition at date 1 from a talented entrepreneur has the same effect it had in section 1.3: it eliminates horizontal structures if the pledgeable income of firm B is larger than the required investment.

${ }^{17}$ In the version of the model that we analyze in this section, pyramids do not have higher deadweight costs relative to horizontal structures. Conditional on the family being able to finance both firms, the family's ex-ante payoff is identical under pyramidal or horizontal structures. However, this is unlikely to be a general conclusion. For example, section 3.2 shows that pyramidal structures might destroy value because of the possibility of overinvestment in firm B. 
and

$$
\bar{r}_{A}-i_{A}+\frac{1}{2}\left[(1-\bar{d}) r_{B}-i_{B}\right]>0
$$

In this case, it is not optimal for the family to rule out pyramids at date 0 .

Under condition in Equation (13), the family cannot set up firm B in an horizontal structure at date 1 , even in the high cash flow state. In this situation it might be efficient for the family to allow pyramids to be formed at date 1 , because pyramids relax the date 1 financing constraint by increasing the cash available for investments. The problem with the pyramid is that because shareholders of firm A expect future expropriation, allowing pyramids to be formed tightens the date 0 financing constraint. The condition in Equation (14) is required for the date 0 constraint to be met if the pyramid is formed only in the high cash flow state. ${ }^{18}$

So far we assumed that firm B can only be set up at date 1 . The next result endogenizes the timing of this decision in the context of the current extension.

Result 7 Suppose the family has access to both projects at date 0. Under the conditions of result 6, the optimal investment policy is to set up firm A first, and then set up firm B in a pyramid if the cash flows of firm A are high.

Result 6 shows that pyramids can only have ex-ante benefits if the sum of the pledgeable incomes of firms $\mathrm{A}$ and $\mathrm{B}$ is lower than the sum of the required investments. This follows from the first condition in result 6 , because $\bar{r}_{A}-i_{A}+(1-d) r_{B}-i_{B}<-\left(1-\frac{i_{A}}{\bar{r}_{A}}\right) \Delta<0$. In this case, the family cannot set up both firms at date 0. Furthermore, as we explained above, the family can still set up firm $\mathrm{A}$ at date 0 and, set up firm B in a pyramid, if the high cash flow state realizes. Thus, pyramids are created following good performance of the existing firms in the group.

\section{Ultimate ownership and diversion}

The simple framework of the previous section generates several results about the conditions under which business groups appear and the type of structures they use. However, because we assume that diversion is independent of ownership concentration, the family can fully dilute ownership

\footnotetext{
${ }^{18}$ We show in the appendix that if conditions 13 and 14 hold, the family can never raise enough funds to set up firm $\mathrm{A}$ at date 0 , and set up the pyramid in both states at date 1, because in this case shareholders of firm A cannot break-even.
} 
without any implications for value. Thus the previous model is not well suited to address the question of concentration of cash flow rights in pyramidal firms. Furthermore, because diversion is the same irrespective of the organizational form, the model does not have predictions for the relationship between the pyramidal organizational form and diversion.

In this section, we endogenize diversion and the ultimate ownership concentration of firm B. To this end, we assume that diversion is costly. In particular, we assume that $c(0, k)=0, c_{d}>0$, $c_{d d}>0$, and $c_{d k}>0$. These assumptions imply that a high degree of investor protection (high $k$ ) corresponds to a high cost of diversion.

When diversion is costly, the family tries to reduce it by maximizing its ultimate ownership concentration in firm B. In other words, the family chooses the structure that allows it to finance the new firm with the smallest equity issuance. Because pyramids allow the family to use firm A's cash to finance firm B, it might appear that they provide the family with a higher financing capacity. However, the financing cost of using a pyramid is that the non-family shareholders in firm A receive shares that could have been sold to the market, had the horizontal structure been used. Thus, which structure maximizes financing capacity depends on the relation between the market price and the implicit price paid by non-family shareholders of firm A. For example, when diversion is expected to be high, the market price is low and so the pyramidal structure is the one that maximizes financing capacity. Conversely, when diversion is expected to be low, the horizontal structure is the one that maximizes financing capacity.

\subsection{Optimal ownership concentration in each structure}

We start solving the model at date 2 . In both structures, $d(\omega, k)$ is defined by $d=\arg \max _{d} \omega(1-$ $d)+d-c(d, k)$, where $\omega$ is the family's ultimate ownership concentration in firm B. Assuming an interior solution, $d(\omega, k)$ satisfies the first order condition of this problem, $c_{d}(d(\omega, k), k)=1-\omega$.

It follows from the properties of $c(\cdot, \cdot)$ that diversion is decreasing in ownership concentration $\left(d_{\omega}<0\right)$ and in the level of investor protection $\left(d_{k}<0\right)$. We define the NPV net of diversion

costs as $N P V=r-i-c(d, k) r$. We have that $\frac{\partial N P V}{\partial \omega}>0$ because higher ultimate ownership concentration reduces diversion and consequently the total cost of diversion.

Moving back to date 1, the family solves the problem in Equations (4) and (8). We obtain the following result. 
Result 8 In both structures the family maximizes its ownership concentration in firm $B$, subject to raising sufficient funds to finance this firm. For this reason the internal resources contributed are set to the maximum possible $\left(R_{I}^{H}=\alpha c\right.$ and $\left.R_{I}^{P}=c\right)$. Also, the ultimate ownership concentration is set at the highest value that is consistent with the financing requirement. That is, for the horizontal structure, if $\alpha c \geq i$, then $\omega^{H}=1$, and if $\alpha c<i, \omega^{H}$ is the maximum value that satisfies

$$
\widetilde{R}^{H}\left(\omega^{H}\right) \equiv \alpha c+\left(1-\omega^{H}\right)\left(1-d\left(\omega^{H}, k\right)\right) r=i
$$

For the pyramidal structure, if $c \geq i$, then $\omega^{P}=\alpha$ (i.e., $\beta^{P}=1$ ), and if $c<i, \omega^{P}$ is the maximum value that satisfies

$$
\widetilde{R}^{P}\left(\omega^{P}\right)=c+\left(1-\frac{\omega^{P}}{\alpha}\right)\left(1-d\left(\omega^{P}, k\right)\right) r=i
$$

The function $\widetilde{R}^{H}\left(\omega^{H}\right)$ is the amount of funds raised in the horizontal structure when the family contributes $\alpha c$ of its own funds and the ultimate ownership concentration in firm B is $\omega^{H}$. This expression is found by replacing $R_{I}^{H}=\alpha c$ and $d=d\left(\omega^{H}, k\right)$ into the expression for $R^{H}$ (Equation 3 ). Similarly, $\widetilde{R}^{P}\left(\omega^{P}\right)$ represents the funds collected in the pyramidal structure when firm A contributes $c$ and the ultimate ownership concentration in firm B is $\omega^{P}$. This expression is found by replacing $R_{I}^{P}=c$ and $d=d\left(\omega^{P}, k\right)$ into the expression for $R^{P}$ (Equation 7 ).

In the horizontal structure the cost of diversion falls back on the family, who gets the entire NPV of the project. Thus, the family has an incentive to maximize its ownership concentration so as to minimize diversion $\left(d_{\omega}<0\right)$.

In the pyramidal structure, it is not a priori clear that the family wants to minimize diversion because reducing diversion has two opposing effects on the family's payoff (see Equation (6)). First, it reduces the cost of diversion and hence increases the NPV of the firm B. However, lower diversion also means that the family has to share a greater fraction of the NPV with existing shareholders (the term $(1-\alpha)[(1-d) r-i]$ goes up). However, we show that the family always wants to maximize ownership concentration even in this case. The reason is that the family bases its diversion decision on its ex-post stake in firm $\mathrm{B}, \omega^{P}=\alpha \beta^{P}$, and diverts $d\left(\alpha \beta^{P}, k\right)$. Nevertheless, from the viewpoint of date 1 , the family gets a fraction $\alpha$ of the non-diverted revenue (because diversion is priced in). That is, from the viewpoint of date 1 , optimal diversion is $d(\alpha, k)$. Because the ex-post stake is lower than $\alpha$, the family diverts too much from the perspective of date 1, and hence benefits from lower diversion. 


\subsection{Comparison of the pyramidal and horizontal structures}

We can now use Result 8 to find the optimal ownership levels for each structure. We then compare the family's maximum payoff with each structure to determine which of the two is optimal. To compare the payoff under the two structures, we first need to know the relation between $\omega^{H}$ and $\omega^{P}$.

\subsubsection{The relation between the ultimate ownership concentration levels $\omega^{H}$ and $\omega^{P}$}

We concentrate on the most interesting cases, those in which the family needs to rely on the external market to finance firm B (i.e., $c<i$ ). The optimal ownership concentration levels, $\omega^{H}$ and $\omega^{P}$, are given in Result 8. Rearranging Equations (15) and (16) leads to:

$$
\begin{aligned}
& \widetilde{R}^{H}\left(\omega^{H}\right)=\alpha c+\left(1-\omega^{H}\right)\left(1-d\left(\omega^{H}, k\right)\right) r=i, \text { and } \\
& \widetilde{R}^{P}\left(\omega^{P}\right)=\alpha c+\left(1-\omega^{P}\right)\left[m\left(\frac{\alpha c}{\omega^{P}}\right)+(1-m)\left(1-d\left(\omega^{P}, k\right)\right) r\right]=i,
\end{aligned}
$$

where $m \equiv \frac{\omega^{P}}{1-\omega^{P}}\left(\frac{1}{\alpha}-1\right)$.

Equations (17) and (18) highlight an important distinction between a pyramidal and an horizontal structure. In an horizontal structure, there are only two types of shareholders of firm B: the family and the new shareholders. The family keeps a fraction $\omega^{H}$ of firm B and contributes all of its wealth, $\alpha c$. New shareholders buy a fraction $1-\omega^{H}$ of the firm and pay $\left(1-\omega^{H}\right)\left(1-d\left(\omega^{H}, k\right)\right) r$, where $\left(1-d\left(\omega^{H}, k\right)\right) r$ is the market price per share. In a pyramidal structure, there are three types of shareholders: the family, non-family shareholders of firm A and new shareholders. The family retains a fraction $\omega^{P}$ of firm $\mathrm{B}$ and contributes $\alpha c$. The remaining fraction, $1-\omega^{P}$, is distributed between non-family shareholders of firm A and new shareholders of firm B. ${ }^{19}$ The term in brackets in Equation (18) reflects the average price of these shares in which $m$ and $1-m$ are the proportion of each of these two types of shareholders. New shareholders pay the market price of firm B, $\left(1-d\left(\omega^{P}, k\right)\right) r$, while non-family shareholders of firm A pay an implied price of $\alpha c / \omega^{P}$. The latter price follows from the fact that non-family shareholders of firm A contribute their share of retained earnings $(1-\alpha) c$ for a fraction $(1-\alpha) \beta^{P}$ of firm $\mathrm{B}$. Thus, the implied price is $(1-\alpha) c /\left[(1-\alpha) \beta^{P}\right]=\alpha c / \omega^{P}$.

\footnotetext{
${ }^{19}$ Non-family shareholders of firm A indirectly own $(1-\alpha) \beta^{P}=\left(1-\omega^{P}\right) m$ of firm $\mathrm{B}$, and new shareholders hold $1-\beta^{P}=\left(1-\omega^{P}\right)(1-m)$ of firm $\mathrm{B}$.
} 
As Equations (17) and (18) indicate, even though the family has access to the entire stock of earnings of firm A when it chooses the pyramidal structure, this does not necessarily translate into a financing advantage. The reason is that, in the pyramidal structure, non-family shareholders receive shares, which could have been sold to the market if the horizontal structure had been used instead. Thus, the horizontal structure has the financing advantage when the market price is higher than the implied price paid by shareholders of firm A. More precisely, suppose that we compare the funds raised in each structure for the same level of ultimate ownership concentration in firm B, $\omega$. Simple algebra shows that $\widetilde{R}^{H}(\omega)>\widetilde{R}^{P}(\omega)$ (the horizontal structure has the financing advantage) if and only if $(1-d(\omega, k)) r>\frac{\alpha c}{\omega}$ (the market price is higher than the implied price).

To illustrate how the optimal choice of structure is affected by the different parameters we use Figure 1. In this figure we focus on a single parameter, the investment required, $i$ (Results 9 and 10 present the general case). In the horizontal axis we have the ultimate ownership of the family in firm B $\left(\omega^{H}\right.$ and $\left.\omega^{P}\right)$. In the vertical axis we have the amount raised in each structure for a given ownership concentration.

First, we plot the values of $\widetilde{R}^{H}$ and $\widetilde{R}^{P}$ as a function of the family's ultimate ownership in firm $\mathrm{B}, \omega{ }^{20}$ We define $\bar{\omega}$ as the ultimate ownership concentration for which the family raises the same amount of funds with either structure (we call this amount $\bar{i}$ ). It must be then that at $\omega=\bar{\omega}$, the implied price paid by non-family shareholders of firm A equals the market price paid by new shareholders of firm B. For higher ownership concentration levels, $\omega>\bar{\omega}$, the market price increases (because there is less diversion in firm B), and the implied price declines (because non-family shareholders receive more shares but contribute the same amount). Thus, as explained above, the family raises more funds with the horizontal structure $\left(\widetilde{R}^{H}(\omega)>\widetilde{R}^{P}(\omega)\right)$. Conversely, for lower ownership concentration levels, $\omega<\bar{\omega}$, the market price of firm B is lower than the implied price. In this case, the family raises more funds with the pyramidal structure $\left(\widetilde{R}^{H}(\omega)<\widetilde{R}^{P}(\omega)\right)$.

Second, we show the optimal ownership concentration levels, $\omega^{H}$ and $\omega^{P}$ for two investment levels $i_{1}$ and $i_{2}$ with $i_{1}<\bar{i}<i_{2}$. Because the family raises just enough funds to set up firm $\mathrm{B}$, the optimal ownership concentration in the pyramidal (horizontal) structure is such that $\widetilde{R}^{P}\left(\omega^{P}\right)=i$ $\left(\widetilde{R}^{H}\left(\omega^{H}\right)=i\right)$. As the Figure shows, for the low investment level, $i_{1}$, the ultimate ownership in the

\footnotetext{
${ }^{20}$ Figure 1 only shows the relevant part of the curves. Both $R^{H}$ and $R^{P}$ might have increasing and decreasing regions. However, the solution is never in an increasing region, because a slightly higher ownership concentration would increase NPV $\left(\frac{\partial N P V}{\partial \omega}>0\right)$ and at the same time allow the family to raise more funds.
} 
pyramidal structure is lower than that in the horizontal structure $\left(\omega_{1}^{P}<\omega_{1}^{H}\right)$. Conversely, at the high investment cost, $i_{2}, \omega_{2}^{P}>\omega_{2}^{H}$.

\subsubsection{The non-diverted NPV at the optimal ownership concentration}

The non-diverted NPV is negative for both structures when $i>\bar{i}$, and is positive for both structures when $i<\bar{i}$. Consider the case in which $i>\bar{i}$. In this case, Figure 1 shows that $\omega^{H}<\omega^{P}<\bar{\omega}$. But we argued above that when $\omega<\bar{\omega}$, the implicit price paid by non-family shareholders of firm $\mathrm{A}$ is higher than the market price. In other words, the non-family shareholders of firm A realize a negative NPV in their investment in firm B, or equivalently, the non-diverted NPV of firm B is negative. A similar argument holds for the other case.

\subsubsection{The choice of structure}

The final step is to compare the maximum payoff with each structure (Equations (2) and (6)) at the optimal ownership concentration. The key result is that, if $i<\bar{i}$, the horizontal structure is chosen, and if $i>\bar{i}$, the pyramidal structure is chosen. When $i<\bar{i}$, the ultimate ownership in the horizontal structure is higher. A more concentrated ownership leads to a higher NPV (because $\frac{\partial N P V}{\partial \omega}>0$ ). In addition, the non-diverted NPV in this region is positive and therefore it is better to capture this value entirely (horizontal structure) than to share it with the non-family shareholders of firm A (pyramidal structure). Conversely, when $i>\bar{i}$, the ultimate ownership in the pyramidal structure is higher and the non-diverted NPV of firm B is negative. Thus, in this region, the pyramid is the best option for the family.

We summarize the above discussion in the following Result.

Result 9 Let $(\bar{\alpha}, \bar{c}, \bar{r}, \bar{i}, \bar{k})$ be parameters such that $\omega^{H}=\omega^{P}=\bar{\omega}$. For $i>\bar{i}$, the ultimate ownership in a pyramid is higher $\left(\omega^{P}(i)>\omega^{H}(i)\right)$, the non-diverted NPV of firm $B$ is negative under both structures and, if feasible, the pyramidal structure is chosen (identical results hold when $r<\bar{r}$ and when $k<\bar{k})$. For $i<\bar{i}$, the ultimate ownership in a pyramid is lower $\left(\omega^{P}(i)<\omega^{H}(i)\right)$, the non-diverted NPV of firm B is positive under both structures and the horizontal structure is always chosen (identical results hold when $r>\bar{r}$ and when $k>\bar{k}$ ).

As the above discussion illustrates, the model with endogenous ownership produces essentially the same results regarding pyramidal and horizontal structures that we described in section 1. 
The relative size of the family's ultimate cash flow stake in the pyramidal and in the horizontal structure depends on the parameter values. For some parameter values we have that $\omega^{P}>\omega^{H}$, and for others, $\omega^{P}<\omega^{H}$. However, result 9 cannot be taken to the data because it compares the hypothetical values of ownership concentration that would arise if each structure were to be chosen. It does not compare the observed (or effectively chosen) ownership concentration levels. The following result establishes that relation.

Result 10 Suppose that different structures are the result of variation in $r, i$ or $k$ (one by one). The ultimate ownership concentration level observed in any pyramidal structure is lower than the ultimate ownership observed in any horizontal structure. It follows directly that diversion from firm $B$ is higher in pyramids.

This result is a direct implication of Result 9 and be understood using Figure 1. The pyramidal structure is chosen when $i>\bar{i}$. These investment levels map into ownership concentrations that satisfy $\omega^{P}<\bar{\omega}$. Also, the horizontal structure is chosen whenever $i<\bar{i}$. The associated ownership concentration levels are $\omega^{H}>\bar{\omega}$.

Finally, we analyze the determinants of the threshold $\bar{\omega}$.

Result 11 The threshold of ultimate ownership below which the pyramid is chosen, $\bar{\omega}$, is decreasing in investor protection.

At the threshold $\bar{\omega}$, the non-diverted NPV of firm B is zero. As investor protection deteriorates, ownership concentration must increase to keep the diversion level and the NPV constant. The implication of this result is that, in poor investor protection countries, it is more likely that families hold a large ultimate cash flow stake in pyramidal firms.

\subsection{Discussion}

We show in Result 10 that the observed ultimate ownership in a pyramidal structure is lower than in an horizontal structure. The observation that ultimate ownership in a pyramid is low has been made informally by many authors. The traditional argument is that the chain of control mechanically reduces ultimate ownership. As Result 9 indicates, however, if one compares the ultimate ownership a firm would have under a pyramid and under a horizontal structure, it is not always the case that 
ultimate ownership is lower in a pyramidal structure. The traditional argument ignores the fact that, because of the presence of retained earnings, the pyramid might have a financing advantage, and consequently, the family might need to sell fewer shares when using this structure to finance the new firm. Our argument in Result 10 is different. The pyramid is set up when the investment required is high, revenues are low and/or investor protection is low. But in these situations more shares need to be sold to finance the set up costs of the new firm. This selection effect is the reason that ultimate ownership is lower in a pyramid than in a horizontal structure.

A similar argument holds for diversion. The traditional view is that diversion is higher in a pyramidal structure because the chain of control reduces the family's ultimate ownership. This argument ignores the fact that families are interested in reducing diversion because its cost falls back to them (see Result 8). Our model is consistent with the empirical observation that there is more diversion in pyramids even when families are interested in minimizing diversion. In our model some types of firms end up in horizontal structures and other types of firms end up in pyramidal structures. Diversion is higher in firms that end up in pyramidal structures. However, for the firms that are optimally set up in pyramids, diversion would have been even higher (because of a lower ultimate ownership concentration) if the horizontal structure had been chosen instead. That is, in our model it is not the case that the pyramidal structure itself increases diversion.

Result 10 shows that the observed ultimate ownership in pyramids is lower than in horizontal structures. It does not imply that ownership concentration should be low in a pyramid in an absolute sense. In fact, the threshold of ultimate ownership at which the family switches to the pyramidal structure, $\bar{\omega}$, can be quite high. If, for instance, this threshold is strictly above $50 \%$, some pyramidal firms will have ultimate ownership concentration around 50\%. Clearly, for these firms, the family could have achieved the same degree of control by simply holding shares directly. Yet, the family chooses the pyramid because of its financing and payoff advantages described above. Depending on the parameter values, our model can also predict very small ownership concentration in pyramidal firms. Thus, unlike the traditional argument for pyramids, our model accommodates both high and low ownership concentration in pyramidal firms. We see this as a strength of the model because the empirical evidence indicates that both cases are common. 


\section{Extensions}

In this section we consider two extensions of our basic framework. First, we discuss a few reasons why a pyramid might be different than a single firm comprising of firms A and B. Second, we analyze the possibility of variable scale of investment in firm B.

\subsection{Should firm B be a separate firm or a division?}

Our analysis so far defines a pyramid as the structure that results when firm A sets up firm B. However, in addition to this feature, the definition of a pyramid requires firm B not to be whollyowned by firm A. Otherwise, one could think of firm B simply as a project of firm A.

There are several reasons outside our model for why a controlling shareholder might wish to separately list a firm (see Morck, Wolfenzon and Yeung, 2005, for a review of the relevant literature). The potential benefits include the option to separately file for bankruptcy while preserving the assets of the other companies in the group, the possibility of offering better incentives and more control for middle managers, and an increase in transparency that stems from the information in stock prices. Our model, augmented with any of these mechanisms, would produce pyramidal structures in which the two firms are legally independent firms.

One possibility that is related to our model is that the diversion technology might depend on the ownership structure chosen for firm B. ${ }^{21}$ For example, two independent projects might be more transparent than a single diversified conglomerate composed of these two projects, specially when the projects are in different industries. It can be argued that higher transparency would make it more difficult to divert or, in the terminology of our paper, that transparency increases $k{ }^{22}$ Under this assumption, whether the family wants to set up a pyramid (separate legal entities) or a single firm in which firm B is a wholly-owned subsidiary of firm A, depends on whether A and B are in the same industry. If $\mathrm{A}$ and $\mathrm{B}$ are in different industries, the family would prefer a pyramid to a diversified conglomerate because that structure increases transparency and commits the family not to divert. If, on the other hand, A and B are in the same industry, then there is a smaller loss of transparency from having firm A own $100 \%$ of the shares of firm B. This argument suggests that separate companies in pyramids should be more likely to correspond to separate industry ventures,

\footnotetext{
${ }^{21}$ In the benchmark model, as in section 3.1.1 below, the maintained assumption is that the choice of ownership structure does not affect the diversion technology.

${ }^{22}$ We thank one of our referees for suggesting this argument.
} 
while same industry expansion could be done within existing firms.

Next, we consider an extension of our basic framework that can also distinguish between a pyramid and a conglomerate, even if the choice of ownership structure has no direct effect on the diversion technology.

\subsubsection{Within-country variation in the degree of investor protection}

We focus on the cases in which the family chooses the pyramidal structure, and analyze the optimal financing of firm B. This financing can take the form of sale of shares of firm A, of firm B, or a combination of the two. We show that in a large number of cases it is optimal for the family to sell shares of firm B directly to the market, i.e., it is optimal for firm A to retain less than $100 \%$ of the cash flow rights of firm B. In these cases, it is clear that the resulting structure is a pyramid.

To analyze this question we need a model in which the optimal ownership concentration is well-defined. For that reason we use the model with costly diversion of section 2 . In addition, we augment that model by allowing for the possibility of diversion from firm A. Because we model diversion from both firms $\mathrm{A}$ and $\mathrm{B}$, we can analyze the trade-off between selling shares of these firms to raise funds.

In section 2 , the parameter $k$ in the cost of diversion $c(d, k)$ is common to all firms in a country. The underlying assumption is that all firms are subject to the same laws, regulations, and other institutions that protect outside investors. However, even though there is an important common component in investor protection, there is also evidence of within-country variation (Durnev and Kim (2005)). The reason for this firm-specific heterogeneity can be purely technological: some industries are inherently more obscure than others (Durnev, Morck and Yeung (2004)). It is also the case that firms can take actions to modify the degree of protection they provide. For example, firms can hire more or less outside directors, have their books audited by a reputable accounting firm, etc. Accordingly, in this section we assume that there is within-country variation in the degree of investor protection offered by firms by letting $k_{A}$ be potentially different from $k_{B}$, where $k_{A}$ and $k_{B}$ are the parameters in the cost of diversion function for firms $\mathrm{A}$ and $\mathrm{B}$, respectively. However, we maintain the assumption that there is a significant country component. This assumption is consistent with Doidge, Karolyi, and Stulz (2004), who find that most of the variation in individual

firm corporate governance measures is driven by country characteristics. We also maintain the 
assumption that $k_{A}$ and $k_{B}$ are independent of the choice of ownership structure.

As in section 2, we consider a model that starts at date 1 . At this date the family has a stake $\alpha_{1}$ in firm $\mathrm{A}$ and the possibility of setting up firm B appears. Instead of assuming that firm $\mathrm{A}$ generates cash flows at date 1 , we assume that it only generates a cash flow, $r_{A}$, at date 2 . Of course, the cash flow $r_{A}$ that occurs at date 2 can be converted into a date- 1 cash flow by selling claims against it. However, because we introduce costly diversion from firm A, this conversion will entail deadweight costs. The goal of the family is to set the ownership structure of firms A and B so as to raise the necessary funds in the most cost-efficient way.

We show in the Appendix that, whenever $k_{B}>k_{A}$, it is optimal to sell shares of firm B directly to the market. The family prefers to sell shares of the firm with a higher diversion cost, because a higher cost helps the family commit to low levels of diversion and thus to an overall lower deadweight cost. Since firm A holds a stake in firm B, the family could sell rights to the cash flows of firm B indirectly by selling shares of firm A. However, when $k_{B}>k_{A}$, it is more efficient to sell shares of firm B while minimizing the number of shares of firm A that the family sells. To achieve this goal, the family needs to sells shares of firm B directly.

\subsubsection{Discussion}

We acknowledge that there are many potential reasons outside our model for firm B to be a separate legal entity. Nevertheless, it is important to stress that most of these arguments cannot, on their own, explain why the family would not prefer to create a horizontal business group because, in this structure, firms are also legally independent. Furthermore, these stories do not explain the existence of the business group in the first place. In this sense, we believe the results and ideas in this section are complementary to those in sections 1 and 2.

An important question, however, is whether the need for additional arguments to differentiate pyramids from single firms changes the nature of the empirical implications of our model. The answer is that it depends on whether these additional arguments are orthogonal to the firm and country characteristics that are conducive to the family using firm A to set up firm B, or whether they are correlated to these characteristics in a way that invalidate our previous implications.

We analyze this question in the context of the model of section 3.1.1. As shown in sections 1.3 and 2, whether firm B is set up by firm A or directly by the family is determined by the absolute 
value of $k_{B}$, and also by the inherent profitability of firm $\mathrm{B}$ (the parameters $r_{B}$ and $i_{B}$ ).

Consider first the empirical prediction that pyramids should be more common in poor investor protection countries. If there is a country component in the determination of $k$ (Doidge, Karolyi, and Stulz (2004)) then it is more likely that firm B will be set up by firm A in poor investor protection countries. However, this result does not guarantee that there will be more pyramidal firms in these countries. If, for some reason, firm A is also more likely to set up firm B as a whollyowned subsidiary in countries with poor investor protection, then our result will break down. However, in section 3.1.1 we have shown that, conditional of firm A setting up firm B, whether shares of firm B are sold directly to the market (pyramid) or not (wholly-owned subsidiary) depends only on the relative magnitudes of $k_{A}$ and $k_{B}$. Because there is no reason to expect the probability of $k_{B}>k_{A}$ to vary systematically with investor protection, the proportion of pyramids to whollyowned subsidiaries should not vary systematically across countries.

In addition, we show in the appendix that whether the family prefers a pyramid or a whollyowned subsidiary does not depend of the inherent profitability of firm B. We conclude that the additional considerations in section 3.1.1 do not change the empirical implications that we derived in sections 1.3 and 2 .

\subsection{Variable scale and overinvestment in pyramids}

In this section we allow the family to choose the size of the investment in firm B. We use the model of section 1.3, with one modification. Firm B now produces a cash flow $r(i)$ at date 2 when an amount $i$ is invested at date 1 . The function $r(i)$ satisfies $r^{\prime}()>0,. r^{\prime \prime}()<$.0 and $\lim _{i \rightarrow 0} r^{\prime}(i)=\infty$. The expressions for $U^{P}, U^{H}, R^{P}$, and $R^{H}$ are identical to those in section 1.3, except that $r(i)$ replaces $r$. The family computes the optimal investment in each structure and then chooses the one with the highest payoff. We show in the appendix that result 1 essentially holds in this extension:

Result 12 Let the first best level of investment be defined by $r^{\prime}\left(i_{F B}\right)=1$. If $(1-\bar{d}) r\left(i_{F B}\right)-i_{F B}<0$, the pyramid is always chosen.

The intuition for this result is very similar to that in section 1.3, with the additional complication that the level of investment is now endogenous. The key expression, $(1-\bar{d}) r(i)-i$, should now be evaluated at the first best level of investment $\left(i_{F B}\right)$, which maximizes the total NPV of firm B and is 
consequently the optimal level of investment in the horizontal structure. If $(1-\bar{d}) r\left(i_{F B}\right)-i_{F B}<0$, then the pyramid yields a higher payoff than the highest possible payoff under the horizontal structure. In addition, pyramids are associated with greater financing capacity. Thus, pyramids must be optimal. Because the condition that determines whether the pyramid is chosen is almost identical to that in section 1.3 , the comparative statics of result 2 hold.

The analysis in this section has an important additional implication. In section 1.3 we assume that firm B must always be a positive NPV investment, taking into account both security and private benefits. In contrast, the next result shows that the family might have an incentive to make investments in firm B that are on the margin negative NPV. The following proposition characterizes the possibility of overinvestment. ${ }^{23}$

Result 13 Suppose that $i_{F B} \leq c+(1-\bar{d}) r\left(i_{F B}\right)$. If the family chooses the pyramid, it will overinvest (relative to the first best) in firm $B$.

The family generally has incentives to invest more than the first best level in the pyramidal structure because the cost of overinvestment are shared with the existing shareholders of firm A. However, when the condition in Result 13 does not hold, the family will not have the resources to finance investment levels above the first best.

The other reason why we might not observe overinvestment is that the family might prefer to use the horizontal structure, which is always associated with the first best investment level. In particular, result 12 shows that the horizontal structure is more likely to be optimal when firm B's security benefits are high at the first best level of investment. In such cases, the family might choose to forego the private benefits of overinvestment in pyramids and set up a horizontal structure instead.

We conclude that the clearest case for overinvestment in pyramids happens when firm B's security benefits are low (because of high diversion, for example), but the family has accumulated a significant amount of cash in firm A. ${ }^{24}$ In this case the excess availability of cash might effectively destroy value in the pyramid, in the sense that firm B would have produced a higher combination of private and security benefits if the pyramidal structure had been ruled out.

\footnotetext{
${ }^{23}$ We thank one of our referees for suggesting that we pursue this argument.

${ }^{24}$ The underlying logic here is very similar to Jensen's (1986) free cash flow problem.
} 


\section{Empirical Implications}

Our theory generates a number of empirical implications, which we list and discuss here. We also mention empirical and anecdotal evidence that is consistent with our theory, and suggest some additional implications that can be tested in the future. We structure this section by discussing first the implications that are unique to our theory. We then discuss the implications that are shared with the traditional argument.

As discussed in the introduction, the traditional argument for pyramids is that they are devices to separate ownership and control, and entrench the controlling family. However, as the first two empirical observations suggest, considerations other than separation of cash flow from voting rights motivate the creation of pyramidal business groups.

\section{It is possible to observe pyramids in which the controlling family has high cash} flow stakes in member firms, and thus the separation between ownership and control is not large

The literature has a number of examples of pyramids in which the family has achieved substantial deviation from one share-one vote (see La Porta, Lopez-de-Silanes and Shleifer, 1999, and Claessens, Djankov and Lang, 2000). However, there are also many other cases in which the separation achieved is small and does not warrant the use of a pyramid. For example, Franks and Mayer (2001) find in their sample of German firms that, in $69 \%$ of the firms controlled through pyramids, the controlling shareholder could have achieved the same level of control by simply holding shares directly in the firm. The authors conclude that, in Germany, pyramids are not used as a device to achieve control. ${ }^{25}$ In a study of ownership and control of Chilean firms, Lefort and Walker (1999) find that the controlling shareholder owns more cash flow than necessary to achieve control. They compute the ultimate cash flow ownership of the controlling shareholder in all the members of a pyramidal group and find this integrated ownership to be on average $57 \%$. Thus, the separation of

\footnotetext{
${ }^{25}$ Franks and Mayer define $25 \%, 50 \%$ and $75 \%$ as critical control levels and argue that voting power between any of these critical levels provide the same degree of control. They show that in $69 \%$ of their sample of pyramidal firms, the cash flow and control rights do not straddle a control treshold. To see that, when this is the case, the pyramid is not used to separate ownership and control, consider the following example. A family's ultimate cash flow rights in a firm that belong to a pyramid are $55 \%$ and his voting rights are $70 \%$. If the same controlling party held $55 \%$ of the shares directly in the firm, he would have $55 \%$ of the votes (assuming one-share-one-vote). Because $55 \%$ and $70 \%$ are between the same two critical levels, direct holdings in the firm and the pyramid provide the controller with the same degree of control.
} 
ownership and control achieved through pyramids is minimal. Attig, Fischer and Gadhoum (2003) find that, in Canada, the cash flow stake of the controlling shareholder in a pyramid is, on average, $31.78 \%$ while the controlling stake is only a bit higher, $41.68 \%$. Faccio and Lang (2002) report that both dual-class shares and pyramids are commonly used in Western European countries. However, they find large deviations between ownership and control in only a few of the Western European countries they analyze. Demirag and Serter (2003) report similar findings for Turkey, where cash flow and voting rights appear to be closely aligned despite the widespread prevalence of pyramidal structures. Finally, Valadares and Leal (2001) draw a similar picture for Brazil, where according to the authors pyramids do not appear to be a mechanism to deviate from one-share-one-vote.

Our model is consistent with these examples. Even though the ultimate ownership concentration in pyramids is lower than that in horizontal structures, it can still be the case that the ultimate ownership in a pyramid is high in an absolute sense (see section 2.3). In fact, depending on the parameter values, pyramidal firms can have either low or high ultimate ownership concentration (and consequently large or small separation of ownership and control). This is consistent with the evidence that in some pyramids a significant separation is achieved, while in others there is virtually no separation of ownership and control. In addition, Result 11 indicates that violations of the traditional story (pyramidal firms with high ultimate ownership) are more likely to be found in countries with poor investor protection.

2. The family might strictly prefer to create a pyramid, even when restrictions to the issuance of dual-class shares are not binding

Because we identify a rationale for pyramids over and above the separation of cash flow from voting rights, our model can distinguish between pyramids and direct ownership with dual-class shares even if there are no legal restrictions to the use of dual-class shares. Therefore, according to the model, it should not be surprising to find that pyramids arise even if families have not exhausted the possibility of issuing dual-class shares. In contrast, in such cases the traditional story cannot differentiate between a pyramid and a horizontal structure with dual-class shares.

We do observe pyramids in situations in which the family could have achieved the same separation with dual-class shares alone. For example, in Italy, Bianchi, Bianco, and Enriques (2001) measure the ultimate ownership in each firm that belongs to a pyramid, compute the number of 
units of capital that the family controls with one unit of its own capital, and average this ratio for all the firms in a pyramid. As a benchmark, consider a family who holds directly $50 \%$ of the cash flows and votes in a firm. In this case the ratio is 2 . The family can increase this ratio because Italian law allows the issuance of $50 \%$ of the firm's capital in non-voting shares (savings shares or azioni di risparmio). If the family uses the maximum fraction of dual-class shares and retains $50 \%$ of the voting shares (i.e., $25 \%$ of the total capital), it can achieve a ratio of 4 . Bianchi, Bianco and Enriques find that, while some pyramids allow the controlling shareholder to control a large

amount of capital (e.g., the ratio for the De Benedetti group is 10.33 and that for the Agnelli group is 8.86), the ratio for other groups is below 4, and sometimes even below 2 (e.g., for the Berlusconi group, it is 3.66, and for the Pirelli group it is only 1.95). Brazil is another example of a country in which dual-class shares can be issued. The evidence in Valadares and Leal (2001) suggests that pyramids are common despite the fact that many Brazilian firms do not exhaust the possibility of issuing shares with superior voting rights.

Besides these two key implications, our model generates at least two more implications that we believe to be unique to our framework.

\section{Pyramids tend to be created dynamically, following good performance of existing}

\section{family firms}

The timing of the model is exogenously specified in most of the analysis. However, Result 7 endogenizes the timing. It shows that pyramids will not be set up at a single point in time, even when the family has access to both firms at date 0 . Thus, our model predicts that pyramids evolve over time, as a function of the performance of the existing firms in the pyramid.

This implication is consistent with the claim of Khanna and Palepu (2000, p. 869), that one of the most important roles of groups is to set up new firms in which the family and the member firms acquire equity stakes. Aganin and Volpin (2004) describe the evolution of the Pesenti group in Italy, and show that this group was created by adding new subsidiaries to the firms the Pesenti family already owned. One of their conclusions is that, in Italy, business groups expand through acquisitions when they are big and have significant cash resources. Claessens, Fan and Lang (2002) find that firms with the highest separation of votes and ownership (those at the bottom of the pyramid) are younger than those with less separation (those at the top). 
4. Separate companies in pyramids are more likely to correspond to separate industry ventures by the controlling family, and are less likely to be in the same industry. ${ }^{26}$

We argue in section 3.1.1 that, if there is variation in investor protection across firms in a country, some of the group's new firms will have higher investor protection than existing firms. In this case, it is optimal for the family to sell shares of the new firms directly to the market. By doing so total diversion is lower than in the alternative case in which the new firm is set up as a whole-owned subsidiary and capital is raised by selling shares of the parent firm. Implication 4 follows from the observation that, for the same legal and institutional environment (i.e., within the same country), investor protection is more likely to vary across industries than within the same industry (Durnev, Morck, and Yeung (2004)). ${ }^{27}$

We note that, because there are other reasons outside the model why the family might want to separately list group firms (see section 3.1), it is possible to have pyramids composed of firms in similar industries. However, the model does predict that all else constant, multi-industry pyramids should be easier to observe in the data than single-industry ones. We are not aware of any systematic evidence on this implication.

The next two implications are also consistent with the traditional view that pyramids are entrenchment devices that magnify agency costs. However, our theory suggests a different interpretation for the empirical evidence.

5. Diversion is higher in firms placed in a pyramid, than in firms controlled directly by the family. This is not due to the fact that pyramids facilitate diversion. Instead, higher diversion in pyramidal firms is due to a selection effect.

We show that the observed ultimate ownership is lower in pyramidal firms, and thus diversion is higher (result 10). This prediction is consistent with empirical findings that pyramids are associated with high expropriation (Bertrand, Mehta, and Mullainathan, 2002 Bae, Kang and Kim, 2002).

The traditional argument for pyramids is also consistent with a positive (negative) correlation between pyramidal ownership structures and diversion (ultimate ownership). In fact, it is often argued that pyramids are chosen precisely because they allow the family to divert more resources.

\footnotetext{
${ }^{26}$ We thank one of our referees for suggesting this empirical implication.

${ }^{27}$ As we mention in section 3.1, this implication would also follow from the assumption that one-industry firms are more transparent than diversified conglomerates.
} 
The problem with this argument is that, if expropriation is priced, it is not clear why the controlling family has incentives to choose a structure that maximizes expropriation.

In contrast, in our model the family chooses a pyramidal structure to minimize - not to facilitatediversion. In addition, our model is consistent with the empirical evidence that, in a cross-section, we should observe more expropriation in pyramids. This result is driven by a selection effect. When the new firm requires a large investment, generates low revenues, and when investor protection is low, diversion is expected to be high in both structures. In such cases the pyramidal ownership is optimal. In the opposite case (low investment required, high revenues, good investor protection), expropriation is expected to be low under both structures, and the horizontal structure is optimally chosen. This is the reason why our model predicts a positive association between pyramids and expropriation. However, this is not equivalent to the statement that pyramids maximize diversion. In fact, if the family were forced to set up the new firm in a horizontal structure in the parameter region in which pyramids are optimal, ultimate ownership would be lower and diversion higher than if the pyramid structure were used.

\section{Firm value and firm performance are lower in firms that are owned through} pyramids, than in unaffiliated firms or horizontal structures. As in implication 5, in our model this correlation is due to a selection effect.

Our model predicts that projects of lower profitability are undertaken inside pyramids (results 2 and 9). Thus, even if the pyramid does not have a direct negative effect on performance, one should observe a negative relationship between measures of firm value such as Tobin's Q and pyramidal membership because of a selection effect. There is evidence that firms in business groups organized as pyramids have lower Tobin's Q than stand-alone firms and firms organized in horizontal groups (Claessens et al. 2002, Volpin 2002) and that this undervaluation is greater if the controlling shareholder has lower ultimate ownership (Holmen and Hogfeldt, 2004). There is also evidence that the separation of ownership and control is detrimental to performance (Claessens et al 2002, Lemmon and Lins 2003, Lins 2003, Mitton 2002, and Joh 2003). ${ }^{28}$ Finally, Attig, Fischer and Gadhoum (2003) show that low Tobin's Q predicts membership in a pyramidal group. This last result is particularly consistent with the idea that pyramids undertake lower profitability

\footnotetext{
${ }^{28}$ There is also a literature that examines the relationship between valuation and firm membership in business groups, without distinguishing between pyramids and other types of groups. See Khanna and Rivkin (1999), Khanna and Palepu (2000), Fisman and Khanna (2000) and Claessens, Fan, and Lang (2002).
} 
projects. We emphasize that while the negative correlation between pyramidal ownership and firm performance is also a prediction of the traditional argument for pyramids, the particular interpretation of this correlation as a selection effect is unique to our paper.

Finally, the model generates four implications that should also follow from the traditional argument for pyramids. Despite this fact, we discuss these implications to show that our paper does not contradict existing empirical evidence on pyramidal business groups.

\section{Family business groups should be more prevalent in countries with poor investor} protection

In the model, families have a financing advantage over potentially more efficient, but less wealthy entrepreneurs, because families can utilize the funds of the firms they already control. In low investor protection countries, this financing advantage is more important because it is more difficult to raise external finance (see result 3). Thus, the fraction of the corporate sector that ends up in business groups should be higher in such countries.

This implication is in the spirit of Khanna and Palepu (1997, 1999), who argue that business groups arise in countries with underdeveloped markets. However, it could also be consistent with the traditional argument for pyramids, which broadly predicts a greater concentration of corporate control in countries in which control is more valuable (i.e., poor investor protection countries). ${ }^{29}$ We believe there is no systematic evidence on this implication, but there is some scattered and anecdotal evidence. For example, Claessens, Fan and Lang (2002) show that the incidence of business groups is high in developing Asian countries, where more than $50 \%$ of the firms in their sample are affiliated with business groups. Faccio and Lang (2002) report similar results for Europe.

\section{Family business groups are more likely to be organized as pyramids, especially} in countries with poor investor protection

In our model, the conditions that are conducive to the appearance of business groups are also conducive to the choice of pyramids over horizontal structures. Families choose the pyramidal structure if the security benefits associated with the new firm are low (high investment, low revenues and poor investor protection). However, it is precisely in these cases that an outside, talented entrepreneur cannot finance this new venture in the external capital market. As a result, the

\footnotetext{
${ }^{29}$ See for example Bebchuk (1999).
} 
business group is created and the pyramid is used.

As we discuss in section 1.4, if there are other reasons for firm B to be set up in a business group (for example, if the family is also the most efficient owner of firm B), then the business group may be organized horizontally. However, in this case the underlying rationale for the existence of the business group does not necessarily correlate with investor protection. A more general way to state the implication of our model is that the types of business groups that appear because of poor investor protection (in our model those that appear because of financial market underdevelopment) tend to be organized as pyramids. Thus, while business groups are likely to have pyramidal structures in countries with poor investor protection, they might be organized horizontally in other countries with higher investor protection.

The traditional argument also predicts that pyramids should be widely used by the business group's controlling family in order to magnify the separation between ownership and control.

La Porta, Lopez-de-Silanes and Shleifer (1999) show evidence that pyramids are very common in countries with poor investor protection. Another piece of evidence that business groups are typically organized as pyramids is that researchers have treated these two terms as synonymous when analyzing the role of family control in developing countries.

\section{Firms in pyramids are larger, or they are more likely to belong to capital intensive industries}

We show that as the required investment increases firms are more likely to belong to pyramidal business groups (Results 2 and 9). In addition, the extension in section 3.2 we show that pyramids might lead to overinvestment. Both arguments suggest that pyramidal firms should be associated with larger scales of capital investment. Nevertheless, this implication can also be generated by the traditional argument because a greater degree of separation between ownership and control might be needed for the family to control larger firms. Attig, Fischer and Gadhoum (2003) find evidence consistent with this implication, using Canadian data. Claessens, Fan and Lang (2002) also find that in East Asia group firms tend to be larger than unaffiliated firms. Bianchi, Bianco and Enriques (2001) find similar evidence for Italy.

10. When a new firm is added to a pyramidal structure, the existing non-family shareholders of the pyramid realize a negative return 
Results 1 and 9 show that pyramids can only be chosen when the pledgeable income of firm B is lower than the required investment. This condition implies that existing shareholders of firm A realize an ex-post loss when the pyramid is formed. As we show in section 1.5, this does not mean that shareholders also lose in an ex-ante sense because the shares in the parent firm were probably priced to reflect future expropriation.

Because the traditional argument associates pyramids with high agency costs, this implication also appears to be consistent with the usual argument for pyramids. We are not aware of any direct tests of this hypothesis in the empirical literature.

\section{Concluding Remarks}

We believe that a full understanding of the structure of business groups requires an answer to three different questions: 1) why are multiple assets in the hands of a single family, 2) why are these assets grouped into legally independent firms, and 3) what determines the choice of ownership structure of these firms (e.g., pyramidal, horizontal, or more complex structures). In this paper we provide answers to these questions by using a single imperfection: poor investor protection.

The theory explains why families use a pyramidal structure to achieve control of several firms in a business group, as opposed to holding shares directly in these firms (horizontal). It shows that pyramids have both a payoff and a financing advantage over horizontal structures when the amount of diversion is expected to be high (e.g., because investor protection is poor). It also shows that the cases in which the pyramidal structure is optimal for the family are also cases in which the business group itself is more likely to appear. Thus, our theory provides a rationale for why it is so common for business groups to adopt a pyramidal ownership structure.

Our argument departs from the traditional story that pyramids are a device to separate cash flow from voting rights. Because of this feature, our model can generate cases in which pyramidal firms have only minor deviations from one share-one vote. It can also explain why pyramids arise even if the family is free to deviate from one share-one vote with the use of dual-class shares, i.e., it explains why pyramids are different from dual-class shares. Our theory can help understand recent empirical evidence - which is inconsistent with the traditional view of pyramids- that some pyramidal firms are associated with small separation between ownership and control. While some predictions of the model are consistent with existing empirical findings, other predictions are only 
backed by anecdotal evidence. Future empirical work could test these implications in a more systematic way to help us better understand these complex organizations.

Another important issue that could be explored by future theoretical work regards the normative implications of the existence of business groups. We have argued that pyramidal business groups can be efficient for the family, but this is not enough to establish efficiency from the perspective of social welfare. Previous authors have argued that family business groups can have deleterious effects on overall economic efficiency because they foster an inefficient allocation of corporate control through family inheritances (Morck, Stangeland and Yeung, 2000), they hamper the development of external capital markets (Almeida and Wolfenzon, 2005), and they lobby for regulation that impede financial development (Rajan and Zingales, 2003a, 2003b, Morck and Yeung, 2004). A model that blends these ideas into our current framework might generate interesting normative implications regarding pyramidal business groups. 


\section{REFERENCES}

Aganin, Alexander and Paolo Volpin, 2005, History of Corporate Ownership in Italy, in Morck, R., ed.: The History of Corporate Governance around the World: Family Business Groups to Professional Managers (University of Chicago Press, Chicago, IL).

Almeida, Heitor and Daniel Wolfenzon, 2005, Should business groups be dismantled? The equilibrium costs of efficient internal capital markets, Journal of Financial Economics, forthcoming.

Aoki, M. (editor), 1984, The economic analysis of the Japanese firm, (North Holland ).

Attig, Najah, Klaus Fischer and Yoser Gadhoum, 2003, On the determinants of pyramidal ownership: Evidence on expropriation of minority interests, Working paper, Laval University.

Bae, Kee-Hong H, Jun-Koo Kang, and Jin-Mo Kim, 2002, Tunnelling or value added? Evidence from mergers by Korean business groups, Journal of Finance 57, 2695-2740.

Barca, Fabrizio and Marco Becht, 2001, The Control of Corporate Europe (Oxford University Press, Oxford).

Bebchuk, Lucian, 1999, A rent protection theory of corporate ownership and control, NBER working paper 7203 .

Bebchuk, Lucian, Reinier Kraakman and George Triantis, 2000, Stock pyramids, cross-ownership, and dual class equity, in Randall M., ed.: Concentrated Corporate Ownership (University of Chicago Press, Chicago, IL).

Berle, Adolph A., and Gardiner C. Means, 1932, The Modern Corporation and Private Property, (McMillan).

Bertrand, Marianne, Paras Mehta and Sendhil Mullainathan, 2002, Ferreting out tunnelling: An application to Indian business groups, Quarterly Journal of Economics 117, 121-148.

Bianchi, Marcello, Magda Bianco, and Luca Enriques, 2001, Pyramidal groups and the separation between ownership and control in Italy, Working paper, Bank of Italy.

Burkart, Mike, Denis Gromb and Fausto Panunzi, 1998, Why higher takeover premia protect minority shareholders, Journal of Political Economy 106, 172-204.

Burkart, Mike, and Fausto Panunzi, 2002, Agency conflicts, ownership concentration, and legal shareholder protection, Working paper, Stockholm School of Economics.

Cestone, Giacinta, and Chiara Fumagalli, 2004, The strategic impact of resource flexibility in business groups, RAND Journal of Economics, forthcoming.

Claessens, Stijn, Simeon Djankov, Joseph P.H. Fan, and Larry H.P. Lang, 2002, Disentangling the incentive and entrenchment effects of large shareholdings, Journal of Finance 57, 2741-2771.

Claessens, Stijn, Simeon Djankov, and Larry H.P. Lang, 2000, The separation of ownership and control in East Asian Corporations, Journal of Financial Economics 58, 81-112.

Claessens, Stijn, Joseph P.H. Fan, and Larry H.P. Lang, 2002, The benefits of group affiliation: Evidence from East Asia, Working paper, University of Amsterdam.

Demirag, Istemi and Mehmet Serter, 2003, Ownership patterns and control in Turkish listed companies, Corporate Governance 11, 40-51. 
Doidge, Craig, G. Andre Karolyi, and Rene M. Stulz, 2004, Why do countries matter so much for corporate governance? Working paper, University of Toronto and Ohio State University.

Durnev, Art, and E. Han Kim, 2005, To steal or not to steal: firm attributes, legal environment, and valuation, Journal of Finance, forthcoming.

Durnev, Art, Randall Morck, and Bernard Yeung, 2004, Value-enhancing capital budgeting and firm-specific stock return variation, Journal of Finance 59, 65-105.

Dyck, Alexander and Luigi Zingales, 2004, Private benefits of control: An international comparison, Journal of Finance 59, 537-600.

Faccio, Mara, and Larry H.P. Lang, 2002, The ultimate ownership of Western European corporations, Journal of Financial Economics 65, 365-395.

Fisman, Raymond and Tarun Khanna, 2000, Facilitating development: The role of business groups, working paper, University of Columbia and Harvard University.

Franks, Julian, and Colin Mayer, 2001, Ownership and control of German corporations, Review of Financial Studies 14, 943-977.

Friedman, Eric, Simon Johnson, and Todd Mitton, 2003, Propping and tunneling, Journal of Comparative Economics 31, 732-750.

Graham, B. and D. Dodd, 1934, Security Analysis (McGraw-Hill Book Company, Inc., New York.)

Ghatak, Maitreesh and Raja Kali, 2001, Financially interlinked business groups, Journal of Economics and Management Strategy 10, 591-619.

Gomes, Armando, 2000, Going public without governance: managerial reputation effects, Journal of Finance 55, 615-646.

Holmen, Martin, and Peter Hogfeldt, 2004, Pyramidal power, mimeo, Uppsala University and Stockholm School of Economics.

Hoshi, Takeo, and Anil Kashyap, 2001, Corporate Financing and Governance in Japan (MIT Press, Cambridge, MA).

Jensen, Michael, 1986, Agency costs of free cash flow, corporate finance and takeovers, American Economic Review 76, 323-329.

Joh, Sung Wook., 2003, Corporate governance and profitability: evidence from Korea before the economic crisis, Journal of Financial Economics 68, 287-322.

Johnson, Simon, Rafael La Porta, Florencio Lopez-de-Silanes, and Andrei Shleifer, 2000, Tunneling, American Economic Review 90, 22-27.

Khanna, Tarun, 2000, Business groups and social welfare in emerging markets: existing evidence and unanswered questions, European Economic Review 44, 748-61.

Khanna, Tarun, and Krishna G. Palepu, 1997, Why focused strategies may be wrong for emerging countries, Harvard Business Review 75, 41-51.

Khanna, Tarun, and Krishna G. Palepu, 1999, The right way to restructure conglomerates in emerging markets, Harvard Business Review 77, 125-134. 
Khanna, Tarun, and Krishna G. Palepu, 2000, Is group affiliation profitable in emerging markets? An analysis of diversified Indian business groups, Journal of Finance 55, 867-891.

Kim, Se-Jik, 2004, Bailout and conglomeration, Journal of Financial Economics 71, 315-347.

La Porta, Rafael, Florencio Lopez-de-Silanes, and Andrei Shleifer, 1999, Corporate ownership around the world, Journal of Finance 54, 471-517.

Leff, Nathaniel, 1978, Industrial organization and entrepreneurship in the developing countries: The economic groups, Economic Development and Cultural Change 26, 661-675.

Lefort, Fernando, and Eduardo Walker, 1999, Ownership and capital structure of Chilean conglomerates: Facts and hypotheses for governance, Revista ABANTE 3, 3-27.

Lemmon, Michael L., and Karl V. Lins, 2003, Ownership structure, corporate governance and firm value: Evidence from the East Asian financial crisis, Journal of Finance 58, 1445-1468.

Lins, Karl V., 2003, Equity ownership and firm value in emerging markets, Journal of Financial and Quantitative Analysis 38, 159-184.

Mitton, Todd, 2002, A cross-firm analysis of the impact of corporate governance on the East Asian financial crisis, Journal of Financial Economics 64, 215-241.

Morck, Randall, 2003, Why some double taxation might make sense: The special case of intercorporate dividends, Working paper, University of Alberta.

Morck, Randall, and M. Nakamura, 1999, Banks and corporate control in Japan, Journal of Finance 54, 319-339.

Morck, Randall, David Stangeland, and Bernard Yeung, 2000, Inherited wealth, corporate control and economic growth: The Canadian disease, in R. Morck ed.: Concentrated Corporate Ownership (University of Chicago Press, Chicago, IL).

Morck, Randall, Daniel Wolfenzon, and Bernard Yeung, 2005, Corporate governance, economic entrenchment and growth, Journal of Economic Literature, forthcoming.

Morck, Randall and Bernard Yeung, 2004, Family control and the rent-seeking society, Entrepreneurship: Theory and Practice, Vol. 28, p. 391-409.

Myers, Steward C., and Nicholas S. Majluf, 1984, Corporate financing and investment decisions when firms have information that investors do not have, Journal of Financial Economics 13, $187-221$.

Nenova, Tatiana, 2003, The value of corporate voting rights and control: A cross-country analysis. Journal of Financial Economics 68, 325-351.

Pagano, Marco and Ailsa Roell, 1998, The choice of stock ownership structure: agency costs, monitoring and the decision to go public, Quarterly Journal of Economics 113, 187-225.

Perotti, Enrico, and S. Gelfer, 2001, Red barons or robber barons? Governance and investment in Russian financial-industrial groups, European Economic Review 45, 1601-1617.

Rajan, Raghuram G., and Luigi Zingales, 2003a, The great reversals: the politics of financial development in the 20th Century, Journal of Financial Economics 69, 5-50. 
Rajan, Raghuram G., and Luigi Zingales, 2003b, Saving Capitalism from the Capitalists (Random House, Inc., New York)

Shleifer, Andrei, and Daniel Wolfenzon, 2002, Investor protection and equity markets, Journal of Financial Economics 66, 3-27.

Valadares, Silvia M., and Ricardo Leal, Ownership and control structure of Brazilian companies, Working paper, Universidade Federal do Rio de Janeiro.

Volpin, Paolo, 2002, Governance with poor investor protection: Evidence from top executive turnover in Italy, Journal of Financial Economics 64, 61-90.

Zingales, Luigi, 1994, The value of the voting right: A study of the Milan stock exchange experience, Review of Financial Studies 7, 125-148. 


\section{Appendix}

\section{Proof of Result 1}

When $(1-\bar{d}) r>i$, it holds that $U^{H}>U^{P}$ and $\bar{R}^{H} \geq i$. Therefore, the horizontal structure is chosen.

When $(1-\bar{d}) r<i$, it holds that $U^{H}<U^{P}$. In this case, we cannot guarantee that the pyramidal structure is always feasible. However, because $\bar{R}^{P} \geq \bar{R}^{H}$, the pyramidal structure is feasible whenever the horizontal structure is. As a result, the family chooses the pyramidal structure whenever it is feasible (i.e., it is never the case that the pyramid is preferred but only the horizontal is feasible)

Proof of Result 2

The condition $(1-\bar{d}) r<i$ is more likely to hold when $r$ is low, $i$ is high and investor protection is low (i.e., $\bar{d}$ is high).

\section{Proof of Result 3}

If $t<0$, the entrepreneur never owns the firm. If $t>0$, whenever the entrepreneur can finance the required investment $i$, he will set up firm B and thus business groups will not appear. Thus, the condition required for business groups not to appear is that the income that the entrepreneur can pledge to outside investors is enough to finance the investment:

$$
\bar{R}^{E}=(1-\bar{d})(1+t) r \geq i
$$

Clearly, if $r$ is high, $t$ is high and/or $i$ is low, Equation (19) is more likely to hold. Furthermore, an increase in investor protection $k$ decreases diversion $\bar{d}$ and facilitates entrepreneurial finance.

As we claim in footnote 14, notice that if the family can drive out entrepreneurs who are just marginally viable (that is, if $\bar{R}^{E}-i$ is positive but small), then $r$ and $t$ would have to be higher and/or $i$ and $\bar{d}$ would have to be lower to generate entrepreneurial ownership. Such a possibility would thus lead to a result that is qualitatively identical to result 3

Proof of Result 4

By result 1, a horizontal structure can only arise when $(1-\bar{d}) r \geq i$. However, this condition implies that when $t>0, \bar{R}^{E}=(1-\bar{d})(1+t) r \geq i$, and thus the entrepreneur can finance the project. Thus, the business group does not appear. If $t<0$, the family always owns firm $\mathrm{B}$, and the horizontal group appears under the same conditions characterized in result 1

\section{Proof of Result 5}

In order to finance firm $\mathrm{A}$, the family sells a fraction $(1-\alpha)$ of this firm and raises $R$. Because $(1-\bar{d}) r_{B}<i_{B}$, at date 1 the family sets up firm $\mathrm{B}$ in a pyramid. Thus, firm $\mathrm{A}$ does not pay a dividend at date 1 , but rather invests the cash $c=R-i_{A}+r_{A}$ of firm A to set up firm B. To raise additional finance at date 1, firm A sells a stake of $\left(1-\beta_{P}\right)$ of firm $\mathrm{B}$ to the market. We assume (wlog) that firm A raises just enough cash to set up firm $\mathrm{B}$, that is, $R-i_{A}+r_{A}+\left(1-\beta_{P}\right)(1-\bar{d}) r_{B}=i_{B}$. At date 2 , firm A receives dividends of $\beta_{P}(1-d) r_{B}$, which by the previous equation equals $R-i_{A}+r_{A}+(1-\bar{d}) r_{B}-i_{B}$. Because investors in firm A break even, we have that $R=(1-\alpha)\left[R-i_{A}+r_{A}+(1-\bar{d}) r_{B}-i_{B}\right]$, or $R=\frac{1-\alpha}{\alpha}\left[r_{A}-i_{A}+(1-\bar{d}) r_{B}-i_{B}\right]$. Note that as long as $r_{A}-i_{A}+(1-\bar{d}) r_{B}-i_{B}>0$, the family can raise any amount of money at date 0 . In particular, the family can raise enough to fund firm $A$, and to make the pyramid feasible at date 1.

\section{Proof of Result 6}

Consider first the case in which pyramids are ruled out by contract. At date 0 , the family sells a fraction $1-\alpha$ of firm A to raise the set up cost, $i_{A}$ (this is wlog - i.e. can show there is no benefit in raising more). Then $(1-\alpha) \bar{r}_{A}=i_{A}$. Let $\alpha^{*}=1-\frac{i_{A}}{\bar{r}_{A}}$ denote the stake that the family retains in firm A.

The cash that the family holds at date 1 is $\alpha^{*} r_{A}$ and so setting firm B in a horizontal structure is feasible if and only if: $\alpha^{*} r_{A}+(1-\bar{d}) r_{B}>i_{B}$. In the low state this inequality becomes:

$$
-\alpha^{*} \Delta+\bar{r}_{A}-i_{A}+(1-\bar{d}) r_{B}>i_{B}
$$

This inequality never holds since, by assumption, $\bar{r}_{A}-i_{A}+(1-\bar{d}) r_{B}<i_{B}$. In the high cash flow state the horizontal structure is feasible when

$$
\alpha^{*} \Delta+\bar{r}_{A}-i_{A}+(1-\bar{d}) r_{B}>i_{B} .
$$

Consider now the case in which pyramidal structures are not ruled out. In this case, the horizontal structure never arises since $(1-\bar{d}) r_{B}<i_{B}$. At date 0 , the family sells a fraction $1-\alpha$ of firm A and raises $R$. Suppose that investors expect the family to set up firm B in a pyramid only when the cash flows of firm A are high (we will show 
below that it will never be an equilibrium to expect that the family sets up the pyramid when cash flows are low). In case of a low cash flow, the family pays the cash in firm $\mathrm{A}, c=R-i_{A}+\bar{r}_{A}-\Delta$, as dividends and does not set the pyramid. In the case of a high cash flow, the family uses all the cash in firm A to set up firm B in a pyramid. The family sells $1-\beta_{P}$ shares of firm B to raise additional cash to set up firm B. We assume (wlog) that the family raises just enough cash to set up firm $B$, that is:

$$
R-i_{A}+\bar{r}_{A}+\Delta+\left(1-\beta_{P}\right)(1-\bar{d}) r_{B}=i_{B}
$$

At date 2 , firm A receives dividends of $\beta_{P}(1-\bar{d}) r_{B}$, which by the last equation equal $R-i_{A}+\bar{r}_{A}+\Delta+(1-\bar{d}) r_{B}-i_{B}$. We now consider the relation between $R$ and $\alpha$. Because $R$ must equal the expected cash flows to date 0 investors, we have:

or

$$
R=(1-\alpha)\left[\frac{1}{2}\left(R-i_{A}+\bar{r}_{A}-\Delta\right)+\frac{1}{2}\left[R-i_{A}+\bar{r}_{A}+\Delta+(1-\bar{d}) r_{B}-i_{B}\right]\right]
$$

$$
R=\frac{1-\alpha}{\alpha}\left[\bar{r}_{A}-i_{A}+\frac{1}{2}\left[(1-\bar{d}) r_{B}-i_{B}\right]\right] .
$$

To sustain the equilibrium, $R$ needs to be large enough so that the pyramid is feasible only when cash flows are high. That is, we need:

$$
R-i_{A}+\bar{r}_{A}+\Delta+(1-\bar{d}) r_{B} \geq i_{B}
$$

and

$$
R-i_{A}+\bar{r}_{A}-\Delta+(1-\bar{d}) r_{B}<i_{B}
$$

Note that, as long as

$$
\bar{r}_{A}-i_{A}+\frac{1}{2}\left[(1-\bar{d}) r_{B}-i_{B}\right]>0
$$

$R$ can be set to any positive value by an appropriate choice of $\alpha$ (see Equation (21)).

Furthermore, notice that the only possible equilibrium when Equation (22) holds is the one we consider in which shareholders expect the family to set up the pyramid only when cash flows are high. It might seem that $R$ can be set sufficiently high so as to finance the pyramid in all states. However, this is not an equilibrium because if $R$ is sufficiently high to make the pyramid feasible in both states, investors anticipate that the family will always set up firm $\mathrm{B}$ in a pyramid, and the expression for $R$ changes to $R=\frac{1-\alpha}{\alpha}\left[\bar{r}_{A}-i_{A}+(1-\bar{d}) r_{B}-i_{B}\right]$. But the right hand side is always negative so this is not an equilibrium. We can also see from this explanation why it is not possible to have a pyramid only when the cash flows are low. If the pyramid is feasible in the low cash flow state, it will also be feasible in the high cash flow state and the family will not be able to raise any money.

Finally, notice that when Equation (22) holds, but Equation (20) does not, ruling out pyramids eliminates the possibility of setting up firm B, whereas not ruling them out at least allows the family to set up firm B in the high cash flow state. There is a region of the parameter space where it is possible to have both Equation (22) holding but not Equation (20). This region is defined by:

$$
\alpha^{*} \Delta+\bar{r}_{A}-i_{A}+(1-\bar{d}) r_{B}<i_{B}<2\left(\bar{r}_{A}-i_{A}\right)+(1-\bar{d}) r_{B}
$$

Because $2\left(\bar{r}_{A}-i_{A}\right)$ can be greater than $\alpha^{*} \Delta+\bar{r}_{A}-i_{A}$, this inequality is possible.

$\underline{\text { Proof of Result } 7}$

If the pyramid is set up at date 0 , the maximum pledgeable income of firms A and B is $\bar{r}_{A}-i_{A}+(1-d) r_{B}-i_{B}<$ $\left(1-\frac{i_{A}}{\bar{r}_{A}}\right) \Delta+\bar{r}_{A}-i_{A}+(1-d) r_{B}-i_{B}<0$, where the last inequality follow from condition 13 . Thus the family cannot set up the pyramid at date 0 even if firm $B$ is available at that date.

\section{Proof of Result 8}

We just need to show that, in both structures, the family benefits by committing to a low level of diversion. For the horizontal structure, we have $\frac{\partial U^{H}}{\partial d}=-c_{d}<0$. Thus the family gains by reducing diversion.

For the pyramidal case, the optimal diversion level from the perspective of date 1 solves $\frac{\partial U^{P}}{\partial d}=0$ or $1-\alpha=$ $c_{d}(d, k)$, which using the definition of $d(\cdot, \cdot)$ can be expressed as $d(\alpha, k)$. However, diversion is decided at date 2 , when the family ultimate ownership is $\alpha \beta^{P}$. Thus, actual diversion is given by $d\left(\alpha \beta^{P}, k\right)$. Since $\frac{\partial^{2} U^{P}}{\partial d^{2}}=-c_{d d}(d, k) r<0$, the closer $d\left(\alpha \beta^{P}, k\right)$ is to $d(\alpha, k)$, the higher is $U^{P}$. Because $d\left(\alpha \beta^{P}, k\right)>d(\alpha, k)$, the family gains by reducing diversion.

$\underline{\text { Proof of Result } 9}$ 
We first show that for the parameter values $(\bar{\alpha}, \bar{c}, \bar{r}, \bar{i}, \bar{k})$ it follows that $(1-d(\bar{\omega}, \bar{k}))-\bar{i}=0$ and $U^{P}=U^{H}$. By Equations (17) and (18),

$$
\begin{aligned}
\widetilde{R}^{H}(\bar{\omega}) & =\widetilde{R}^{P}(\bar{\omega}) \\
\overline{\alpha c}+(1-\bar{\omega})(1-d(\bar{\omega}, \bar{k})) \bar{r} & =\bar{c}+\left(1-\frac{\bar{\omega}}{\bar{\alpha}}\right)(1-d(\bar{\omega}, \bar{k})) \bar{r} \\
(1-d(\bar{\omega}, \bar{k})) \bar{r} & =\frac{\overline{\alpha c}}{\bar{\omega}} .
\end{aligned}
$$

Thus, as explained in the text, the market price, $(1-d(\bar{\omega}, \bar{k})) \bar{r}$, and the implied price, $\frac{\overline{\alpha c}}{\bar{\omega}}$, are the same. Plugging the last equality into Equation (17) leads to $(1-d(\bar{\omega}, \bar{k})) \bar{r}=\bar{i}$. Now, $U^{P}=\overline{\alpha c}+N P V-(1-\bar{\alpha})[(1-d(\bar{\omega}, \bar{k})) \bar{r}-\bar{i}]=$ $\overline{\alpha c}+N P V=U^{H}$.

Now, we prove another intermediate result. Let $i_{1}>i_{2}>c$, then, it must be that $\omega^{H}\left(i_{1}\right)<\omega^{H}\left(i_{2}\right)$ and $\omega^{P}\left(i_{1}\right)<$ $\omega^{P}\left(i_{2}\right){ }^{30}$ We prove this result only for the horizontal structure (the pyramidal case is identical). Suppose towards a contradiction that $i_{1}>i_{2}>c$ and $\omega^{H}\left(i_{1}\right) \geq \omega^{H}\left(i_{2}\right)$. First, because $\widetilde{R}^{H}(1)=\alpha c<c<i_{2}<i_{1}=\widetilde{R}^{H}\left(\omega^{H}\left(i_{1}\right)\right)$, then by the Intermediate Value Theorem $\left(R_{H}\right.$ is continuous), there exists a $\widehat{\omega} \in\left(\omega^{H}\left(i_{1}\right), 1\right)$ such that $\widetilde{R}^{H}(\widehat{\omega})=i_{2}$. Now, since by assumption $\omega^{H}\left(i_{1}\right) \geq \omega^{H}\left(i_{2}\right)$, it must be that $\widehat{\omega}>\omega^{H}\left(i_{2}\right)$. But this a contradiction because $\omega^{H}\left(i_{2}\right)$ is defined as the highest $\omega$ such that $\widetilde{R}^{H}(\omega)=i_{2}$.

We now prove the result for $i$. Proofs for $r$ and $k$ are identical. We consider the parameter $(\bar{\alpha}, \bar{c}, \bar{r}, i, \bar{k})$ with $i>\bar{i}$. Recall that we are considering only investment levels strictly above $c$, that is $\bar{i}>c$.

By the intermediate result shown above, $\omega^{H}(i)<\omega^{H}(\bar{i})=\bar{\omega}$ and $\omega^{P}(i)<\omega^{P}(\bar{i})=\bar{\omega}$. Also, because $(1-$ $d(\omega, k)) r-i$ is increasing in $\omega$ and decreasing in $i$, and $(1-d(\bar{\omega}, \bar{k})) \bar{r}-\bar{i}=0$, it must be that $\left(1-d\left(\omega^{H}(i), \bar{k}\right)\right) \bar{r}-i<0$ and $\left(1-d\left(\omega^{P}(i), \bar{k}\right)\right) \bar{r}-i<0$.

Next, we show that $\omega^{P}(i)>\omega^{H}(i)$. We showed above that $\left(1-d\left(\omega^{H}(i), \bar{k}\right)\right) \bar{r}-i<0$. Replacing $i=\widetilde{R}^{H}\left(\omega^{H}(i)\right)=$ $\alpha c+\left(1-\omega^{H}(i)\right)\left(1-d\left(\omega^{H}(i), \bar{k}\right)\right) \bar{r}$ into this last inequality and rearranging leads to $\frac{\overline{\alpha c}}{\omega^{H}(i)}>\left(1-d\left(\omega^{H}(i), \bar{k}\right)\right) \bar{r}$. Now, evaluating $\widetilde{R}^{P}$ at $\omega^{H}(i)$ :

$$
\begin{aligned}
\widetilde{R}^{P}\left(\omega^{H}\right) & =\overline{\alpha c}+\left(\frac{\omega^{H}}{\bar{\alpha}}-\omega^{H}\right)\left(\frac{\overline{\alpha c}}{\omega^{H}}\right)+\left(1-\frac{\omega^{H}}{\bar{\alpha}}\right)\left(1-d\left(\omega^{H}, \bar{k}\right)\right) \bar{r} \\
& >\overline{\alpha c}+\left(\frac{\omega^{H}}{\bar{\alpha}}-\omega^{H}\right)\left(1-d\left(\omega^{H}, \bar{k}\right)\right) \bar{r}+\left(1-\frac{\omega^{H}}{\bar{\alpha}}\right)\left(1-d\left(\omega^{H}, \bar{k}\right)\right) \bar{r} \\
& =\overline{\alpha c}+\left(1-\omega^{H}\right)\left(1-d\left(\omega^{H}, \bar{k}\right)\right) \bar{r}=\widetilde{R}^{H}\left(\omega^{H}\right)=i,
\end{aligned}
$$

where the inequality follows from $\frac{\overline{\alpha c}}{\omega^{H}(i)}>\left(1-d\left(\omega^{H}(i), \bar{k}\right)\right) \bar{r}$. Since $\widetilde{R}^{P}\left(\omega^{H}(i)\right)>i>c=\widetilde{R}^{P}(\alpha)$, by the Intermediate Value Theorem, there must be a $\widehat{\omega} \in\left(\omega^{H}(i), \alpha\right)$ such that $\widetilde{R}^{P}(\widehat{\omega})=i$. Because $\omega^{P}(i)$ is defined as the highest $\omega$ such that $\widetilde{R}^{P}(\omega)=i$, it must be that $\omega^{P}(i) \geq \widehat{\omega}$, and consequently $\omega^{P}(i)>\omega^{H}(i)$.

Finally, we compare utilities under both structures

$$
U^{P}=\overline{\alpha c}+N P V\left(\omega^{P}\right)-(1-\bar{\alpha})\left[\left(1-d\left(\omega^{P}, \bar{k}\right)\right) \bar{r}-\bar{i}\right]>\overline{\alpha c}+N P V\left(\omega^{H}\right)=U^{H}
$$

The inequality follows because 1) $N P V\left(\omega^{P}\right)>N P V\left(\omega^{H}\right)$ since $\omega^{P}>\omega^{H}$ and $N P V(\omega)$ is increasing, and 2) $\left(1-d\left(\omega^{P}, \bar{k}\right)\right) \bar{r}-i<0$

\section{Proof of Result 10}

Fix a parameter vector $(\bar{\alpha}, \bar{c}, \bar{r}, \bar{i}, \bar{k})$ such that, for these parameters, $\omega^{H}=\omega^{P}=\bar{\omega}$. Suppose that the different structures are chosen due to variation in $i$ (an identical argument can be made with the other parameters). We know from Result 9 that the pyramidal (horizontal) structure is chosen for $i>\bar{i}(i<\bar{i})$ and that $\omega^{P}(i>\bar{i})<\bar{\omega}$ and $\omega^{H}(i<\bar{i})>\bar{\omega}$. That is, all pyramids we observe have ultimate ownership below $\bar{\omega}$ and all horizontal structures have ultimate ownership above $\bar{\omega}$.

$\underline{\text { Proof of Result } 11}$

Recall that $\bar{\omega}$ is the ultimate ownership concentration at which both the pyramidal and the horizontal structure raise the same amount $i$. That is, it is defined by $\widetilde{R}^{H}(\bar{\omega})=i$ and $\widetilde{R}^{P}(\bar{\omega})=i$. We can re-write this system as

$$
\bar{\omega}(1-d(\bar{\omega}, k)) r=\alpha c
$$

\footnotetext{
${ }^{30}$ This intermediate result is simply saying that to finance a larger investment level, the family needs to sell more shares. The reason why the proof is not trivial is that we cannot gurantee that the functions $R^{H}$ and $R^{P}$ are always decreasing with $\omega$. In fact, there are regions in which these functions are increasing.
} 
and

$$
(1-d(\bar{\omega}, k)) r=i .
$$

Because the system has two equations, for it to hold after a change in $k$, at least two parameters need to change. We consider the effect on $\bar{\omega}$ and $i$. Differentiating the first equation with respect to $k$ leads to $r\left[\bar{\omega}_{k}(1-d)-\bar{\omega} d_{\omega} \bar{\omega}_{k}-\bar{\omega} d_{k}\right]=$ 0 or $\bar{\omega}_{k}=\bar{\omega} d_{k} /\left(1-d-\bar{\omega} d_{\omega}\right)<0$ because $1-d \geq 0, d_{\omega}<0$ and $d_{k}<0$. The solution to $i$ can be found from the second equation.

Proof of the result of section 3.1 that, when $k_{A}<k_{B}$, the family sets $\beta^{P}<1$ when setting a pyramid

To raise funds, firm $\mathrm{A}$ sells a fraction $1-\beta_{2}$ of firm $\mathrm{B}$ and, in addition, issues new shares of its own. Letting $\alpha_{2}$ be the family's final stake in firm $\mathrm{A}$, the amount of funds raised is given by:

$$
R_{P}=\left(1-\frac{\alpha_{2}}{\alpha_{1}}\right)\left(\left(1-d_{A}\right) r_{A}+\beta_{2}\left(1-d_{B}\right) r_{B}\right)+\left(1-\beta_{2}\right)\left(1-d_{B}\right) r_{B}
$$

The first term is the amount collected by selling shares of firm A and the second term is the amount raised by selling shares of firm B. Note that because firm A keeps a fraction $\beta_{2}$ of firm A, the family sells a fraction of firm B indirectly through the sale of shares in firm A.

The family's payoff at date $t_{2}$ is given by:

$$
U^{P}=\alpha_{2}\left(\left(1-d_{A}\right) r_{A}+\beta_{2}\left(1-d_{B}\right) r_{B}\right)+\left(d_{A}-\frac{k_{A} d_{A}^{2}}{2}\right) r_{A}+\left(d_{B}-\frac{k_{B} d_{B}^{2}}{2}\right) r_{B}
$$

where the first term is its security benefits and the last two terms are the diverted amount from each firm net of the cost of diversion.

At date $t_{2}$ the family chooses $d_{A}$ and $d_{B}$ to maximize its payoff. Using the first order conditions (and assuming an interior solution) we get $d_{A}=\left(1-\alpha_{2}\right) / k_{A}$ and $d_{B}=\left(1-\alpha_{2} \beta_{2}\right) / k_{B}$.

From the viewpoint of date $t_{1}$, the goal of the family is to maximize $U^{P}$ subject to $R_{P} \geq i_{B}$ and to the expressions for $d_{A}$ and $d_{B}$. As we have shown before, the fact that diversion is costly implies that it does not pay for the family to raise more funds than the strictly necessary to set up firm B. Thus, at the solution $R_{P}=i_{B}$. Replacing this equality in the family's payoff leads to:

$$
U^{P}=\alpha_{1}\left(\left(1-d_{A}\right) r_{A}+\left(1-d_{B}\right) r_{B}-i_{B}\right)+\left(d_{A}-\frac{k_{A} d_{A}^{2}}{2}\right) r_{A}+\left(d_{B}-\frac{k_{B} d_{B}^{2}}{2}\right) r_{B}
$$

The problem of the family is to chose $\alpha_{2}$ and $\beta_{2}$ to maximize its payoff (Equation (25)) subject to raising enough funds to set up firm B $\left(R_{P} \geq i_{B}\right)$ and to the expressions $d_{A}=\left(1-\alpha_{2}\right) / k_{A}$ and $d_{B}=\left(1-\alpha_{2} \beta_{2}\right) / k_{B}$.

The family's problem is to choose $\alpha_{2}$ and $\beta_{2}$ so as to maximize its payoff. It will be convenient to divide this problem in two steps. First, we fix $\beta_{2}$ and find the optimal $\alpha_{2}$ and the maximum attainable payoff for the given value of $\beta_{2}$. We let $\alpha_{2}\left(\beta_{2}\right)$ and $U^{P}\left(\beta_{2}\right)$ be the optimal value of $\alpha_{2}$ and the maximum attainable payoff, respectively, as a function of $\beta_{2}$. This first maximization problem can be written as

$$
\begin{aligned}
& U^{P}\left(\beta_{2}\right)=\max _{\alpha_{2}} \alpha_{1}\left(\left(1-d_{A}\right) r_{A}+\left(1-d_{B}\right) r_{B}-i_{B}\right)+\left(d_{A}-\frac{k_{A} d_{A}^{2}}{2}\right) r_{A}+\left(d_{B}-\frac{k_{B} d_{B}^{2}}{2}\right) r_{B} \\
& \quad \text { subject to } \\
& R_{P} \geq i_{B}, \\
& d_{A}=\left(1-\alpha_{2}\right) / k_{A}, \text { and } \\
& d_{B}=\left(1-\alpha_{2} \beta_{2}\right) / k_{B},
\end{aligned}
$$

where the objective function comes from Equation (25) and $R_{P}$ is given in Equation (23). The second step is simply to maximize $U^{P}\left(\beta_{2}\right)$ over $\beta_{2}$.

Because the family sells shares to raise funds, the solution has $\alpha_{2} \leq \alpha_{1}$ and $\beta_{2} \leq 1$.It can be shown (by using a similar proof as that of Result 8) that increasing $\alpha_{2}$ towards $\alpha_{1}$ and $\beta_{2}$ towards 1 raises the family payoff. An implication of this fact is that the family does not raise more capital than it needs, that is, at the solution $R_{P}=i_{B}$, which using the expression for $R_{P}$ in Equation (23) can be written as:

$$
\left(1-\frac{\alpha_{2}}{\alpha_{1}}\right)\left(\left(1-d_{A}\right) r_{A}+\beta_{2}\left(1-d_{B}\right) r_{B}\right)+\left(1-\beta_{2}\right)\left(1-d_{B}\right) r_{B}=i_{B}
$$

where $d_{A}=\left(1-\alpha_{2}\right) / k_{A}$ and $d_{B}=\left(1-\alpha_{2} \beta_{2}\right) / k_{B}$. This equation implicitly defines $\alpha_{2}$ as a function of $\beta_{2}$, i.e., it defines $\alpha_{2}\left(\beta_{2}\right)$. The expression for $U^{P}\left(\beta_{2}\right)$ can be found by plugging $\alpha_{2}\left(\beta_{2}\right)$ into the objective function. 
The optimal value of $\beta_{2}$ is the one that maximizes $U^{P}\left(\beta_{2}\right)$. We are only interested in showing that $\beta_{2}<1$. It will be sufficient to show that $\left.U^{P^{\prime}}\left(\beta_{2}\right)\right|_{\beta_{2}=1}<0$.

Differentiating the objective function in Equation (26) and recognizing that $\alpha_{2}$ is a function of $\beta_{2}$ and that $d_{A}=\left(1-\alpha_{2}\right) / k_{A}$ and $d_{B}=\left(1-\alpha_{2} \beta_{2}\right) / k_{B}$ we get:

$$
U^{P \prime}\left(\beta_{2}\right)=\frac{-\left(k_{A} r_{B} \alpha_{2}^{2} \beta_{2}\right)+\alpha_{1} \alpha_{2}^{\prime}\left(k_{B} r_{A}+k_{A} r_{B} \beta_{2}\right)+\alpha_{2}\left(k_{A} r_{B} \alpha_{1}-\left(k_{B} r_{A}+k_{A} r_{B} \beta_{2}^{2}\right) \alpha_{2}^{\prime}\right)}{k_{A} k_{B}}
$$

where we use $\alpha_{2}$ instead of $\alpha_{2}\left(\beta_{2}\right)$ and $\alpha_{2}^{\prime}$ instead of $\alpha_{2}^{\prime}\left(\beta_{2}\right)$ to lighten notation. Next, we obtain $\alpha_{2}^{\prime}\left(\beta_{2}\right)$ by completely differentiating Equation (28) with respect to $\beta_{2}$ and rearranging:

$$
\alpha_{2}^{\prime}\left(\beta_{2}\right)=\frac{k_{A} r_{B} \alpha_{2}\left(1-k_{B}+\alpha_{1}-2 \alpha_{2} \beta_{2}\right)}{-\left(k_{A} r_{B}\left(1+\alpha_{1}\right) \beta_{2}\right)+k_{B}\left(r_{A}\left(-1+k_{A}-\alpha_{1}\right)+k_{A} r_{B} \beta_{2}\right)+2 \alpha_{2}\left(k_{B} r_{A}+k_{A} r_{B} \beta_{2}{ }^{2}\right)} .
$$

Finally, we replace $\alpha_{2}^{\prime}\left(\beta_{2}\right)$ into Equation (29) and evaluate the expression at $\beta_{2}=1$ to obtain

$$
\left.U^{P^{\prime}}\left(\beta_{2}\right)\right|_{\beta_{2}=1}=\frac{\left(k_{A}-k_{B}\right) r_{A} r_{B}\left(\alpha_{1}-\alpha_{2}\right) \alpha_{2}}{-k_{B} r_{A}\left(1+\alpha_{1}-k_{A}\right)-k_{A} r_{B}\left(1+\alpha_{1}-k_{B}\right)+2\left(k_{B} r_{A}+k_{A} r_{B}\right) \alpha_{2}} .
$$

We show that this expression is negative. Note that the numerator is negative. The reason is that $k_{B}>k_{A}$ and $\alpha_{1}>\alpha_{2}(1)$. It is always the case that $\alpha_{1} \geq \alpha_{2}\left(\beta_{2}\right)$ because the family sells some non-negative amount of shares of firm A. However, when $\beta_{2}=1$, the inequality is strict. If not, then $R_{P}$ would be 0 which is not possible because $\alpha_{2}$ and $\beta_{2}$ should be such that $R_{P}=i_{B}>0$.

We now show that the denominator is positive. We do this by deriving a condition that $\alpha_{2}(1)$ must satisfy. We go back to the problem in Equation $(26)$ and solve it for $\beta_{2}=1$. We let $\widehat{R}_{P}\left(\alpha_{2}\right)$ be the expression for the amount raised (given in Equation (23)) as a function of $\alpha_{2}$ when $\beta_{2}=1$ :

$$
\left.\widehat{R}_{P}=\left(1-\frac{\alpha_{2}}{\alpha_{1}}\right)\left(\left(1-d_{A}\right) r_{A}+\left(1-d_{B}\right) r_{B}\right)\right)
$$

By replacing the expressions for $d_{A}=\left(1-\alpha_{2}\right) / k_{A}$ and $d_{B}=\left(1-\alpha_{2} \beta_{2}\right) / k_{B}=\left(1-\alpha_{2}\right) / k_{B}$ into the above expression and differentiating two times with respect to $\alpha_{2}$, we obtain $\frac{\partial^{2} \widehat{R}_{P}}{\partial \alpha_{2}^{2}}=\frac{-2\left(\frac{r_{A}}{k_{A}}+\frac{r_{B}}{k_{B}}\right)}{\alpha_{1}}<0$. This implies that $\widehat{R}_{P}$ first increases and then decreases with $\alpha_{2}$. We let $\bar{\alpha}$ be the value of $\alpha_{2}$ at which $\widehat{R}_{P}$ achieves its maximum. The value of $\bar{\alpha}$ can be found by solving $\frac{\partial \widehat{R}_{P}}{\partial \alpha_{2}}=0$ and is equal to

$$
\bar{\alpha}=\frac{1}{2} \frac{k_{B} r_{A}\left(1+\alpha_{1}-k_{A}\right)+k_{A} r_{B}\left(1+\alpha_{1}-k_{B}\right)}{k_{B} r_{A}+k_{A} r_{B}} .
$$

Note that $\alpha_{2}(1) \geq \bar{\alpha}$. Suppose not, i.e., $\alpha_{2}(1)<\bar{\alpha}$. By increasing $\alpha_{2}$ to $\bar{\alpha}$ two things happen. One is that the amount raised goes up $\left(R_{P}^{\prime}\left(\alpha_{2}\right)>0\right.$ for $\left.\alpha_{2}<\bar{\alpha}\right)$ and also the payoff of the family goes up (we explained above that the payoff of the family increases as $\alpha_{2}$ increases towards $\left.\alpha_{1}\right)$. Thus, it must be that $\alpha_{2}(1) \geq \bar{\alpha}$. Finally, the numerator in Equation (31) satisfies

$$
\begin{aligned}
& -k_{B} r_{A}\left(1+\alpha_{1}-k_{A}\right)-k_{A} r_{B}\left(1+\alpha_{1}-k_{B}\right)+2\left(k_{B} r_{A}+k_{A} r_{B}\right) \alpha_{2} \\
& \geq-k_{B} r_{A}\left(1+\alpha_{1}-k_{A}\right)-k_{A} r_{B}\left(1+\alpha_{1}-k_{B}\right)+2\left(k_{B} r_{A}+k_{A} r_{B}\right) \bar{\alpha} \\
& =0
\end{aligned}
$$

where the inequality follows because $\alpha_{2}(1) \geq \bar{\alpha}$.

In sum, we show that the numerator in Equation (31) is negative and the denominator positive. Therefore $\left.U^{P^{\prime}}\left(\beta_{2}\right)\right|_{\beta_{2}=1}<0$,which implies that the optimal value of $\beta_{2}$ satisfies $\beta_{2}<1$.

Proof of the result of section 3.1 that $r$ and $i$ do not affect the result above

We showed above that, when $k_{A}<k_{B}$, the family sets $\beta^{P}<1$. This result followed from the fact that $\left.U^{P^{\prime}}\left(\beta_{2}\right)\right|_{\beta_{2}=1}<0$. Inspection of Equation (31) shows that the sign of this derivative is not affected by $r$ or $i$.

\section{Proof of Result 12}

If $(1-\bar{d}) r\left(i_{F B}\right)-i_{F B}<0$, then $U^{P}\left(i_{F B}\right)>U^{H}\left(i_{F B}\right)=\max _{i} U^{H}(i)$. Thus, if $\bar{R}^{P}\left(i_{F B}\right) \geq i_{F B}$, then the pyramid is chosen since it yields a higher payoff than the maximum possible payoff under the horizontal structure. 
If $\bar{R}^{P}\left(i_{F B}\right)<i_{F B}$, then the financing constraint will bind in both structures, and investment must be lower than $i_{F B} \cdot{ }^{31}$ The investment levels in this case are determined directly by the financing constraints:

$$
\begin{aligned}
& \bar{R}^{H}(i)=i^{H} \\
& \bar{R}^{P}(i)=i^{P}
\end{aligned}
$$

Since the pyramid has a larger financing capacity, we have $i_{F B}>i^{P}>i^{H}$ in this case. Thus, given that $i_{F B}$ is the first best investment level, $U^{H}\left(i^{P}\right)>U^{H}\left(i^{H}\right)$. Finally, in order for the constraint to bind it must be that $(1-\bar{d}) r\left(i^{P}\right)-i^{P}<0$. Therefore, $U^{P}\left(i^{P}\right)=U^{H}\left(i^{P}\right)-(1-\alpha)\left[(1-\bar{d}) r\left(i^{P}\right)-i^{P}\right]>U^{H}\left(i^{H}\right)$. We conclude that whenever $(1-\bar{d}) r\left(i_{F B}\right)-i_{F B}<0$ the pyramid must be chosen.

If $(1-\bar{d}) r\left(i_{F B}\right)-i_{F B}>0$, on the other hand, we know that $U^{H}\left(i_{F B}\right)>U^{P}\left(i_{F B}\right)$. We also have $\bar{R}^{H}\left(i_{F B}\right)=$ $\alpha c+(1-\bar{d}) r\left(i_{F B}\right)>i_{F B}$, so the horizontal structure can finance the first best investment level. Since $U^{H}\left(i_{F B}\right)=$ $\max _{i} U^{H}(i)$, the family invests at $i_{F B}$ if it chooses the horizontal structure. Nevertheless, optimal investment in the pyramid is not necessarily $i_{F B}$. The investment that yields the largest payoff for the pyramid solves the following problem:

$$
i_{*}^{P}=\arg \max _{i} U^{P}(i) \text {, s.t. } \bar{R}^{P}(i) \geq i
$$

If the financing constraint is not binding, the first order condition is:

$$
\alpha\left[r^{\prime}\left(i^{P}\right)-1\right]+(1-\alpha) d r^{\prime}\left(i^{P}\right)=0
$$

Since $r^{\prime}\left(i^{P}\right)-1>0$ for $i^{P}<i_{F B}$, and $r^{\prime}\left(i^{P}\right)>0$, the investment level that solves this equation is larger than $i_{F B}$. Denote this level of investment by $\widehat{i}$, and let $i_{\max }$ be the maximum amount of investment that a pyramid can finance:

$$
\bar{R}^{P}\left(i_{\max }\right)=i_{\max }
$$

Clearly, $i_{*}^{P}=\min \left(\widehat{i}, i_{\max }\right)$. If $(1-\bar{d}) r\left(i_{F B}\right)-i_{F B}>0$, it must be that $i_{F B} \leq i_{*}^{P}$.

In order for the horizontal structure to be chosen, we must have that $U^{P}\left(i_{*}^{P}\right)<U^{H}\left(i_{F B}\right)$. We can write:

$$
U^{H}\left(i_{F B}\right)-U^{P}\left(i_{*}^{P}\right)=U^{H}\left(i_{F B}\right)-U^{H}\left(i_{*}^{P}\right)+(1-\alpha)\left[(1-\bar{d}) r\left(i_{*}^{P}\right)-i_{*}^{P}\right]
$$

While the first term is always positive, it is possible that $(1-\bar{d}) r\left(i_{*}^{P}\right)-i_{*}^{P}<0$, and that $U^{P}\left(i_{*}^{P}\right)>U^{P}\left(i_{F B}\right)$ if $(1-\bar{d}) r\left(i_{*}^{P}\right)-i_{*}^{P}$ is small enough. We conclude that $(1-\bar{d}) r\left(i_{F B}\right)-i_{F B}>0$ is a necessary, but not necessarily sufficient condition for the horizontal structure to be chosen

\section{Proof of Result 13}

As shown in the proof of result 12, the unconstrained optimal investment in the pyramid $\widehat{(i)}$ is larger than $i_{F B}$, and actual investment is $i_{*}^{P}=\min \left(\widehat{i}, i_{\max }\right)$ where $\bar{R}^{P}\left(i_{\max }\right)=i_{\max }$. If $i_{F B} \leq c+(1-\bar{d}) r\left(i_{F B}\right)=\bar{R}^{P}\left(i_{F B}\right)$, we know that $i_{\max } \geq i_{F B}$, and thus $i_{*}^{P} \geq i_{F B}$

\footnotetext{
${ }^{31}$ Notice that in order for the financing constraint to bind at an investment level $i$ we must have that $(1-\bar{d}) r^{\prime}(i)<1$, such that it is not possible to relax the financing constraint simply by increasing the level of investment. Under this condition, if the the firm cannot finance an investment level $i_{1}$, feasible investment will be necessarily lower than $i_{1}$.
} 


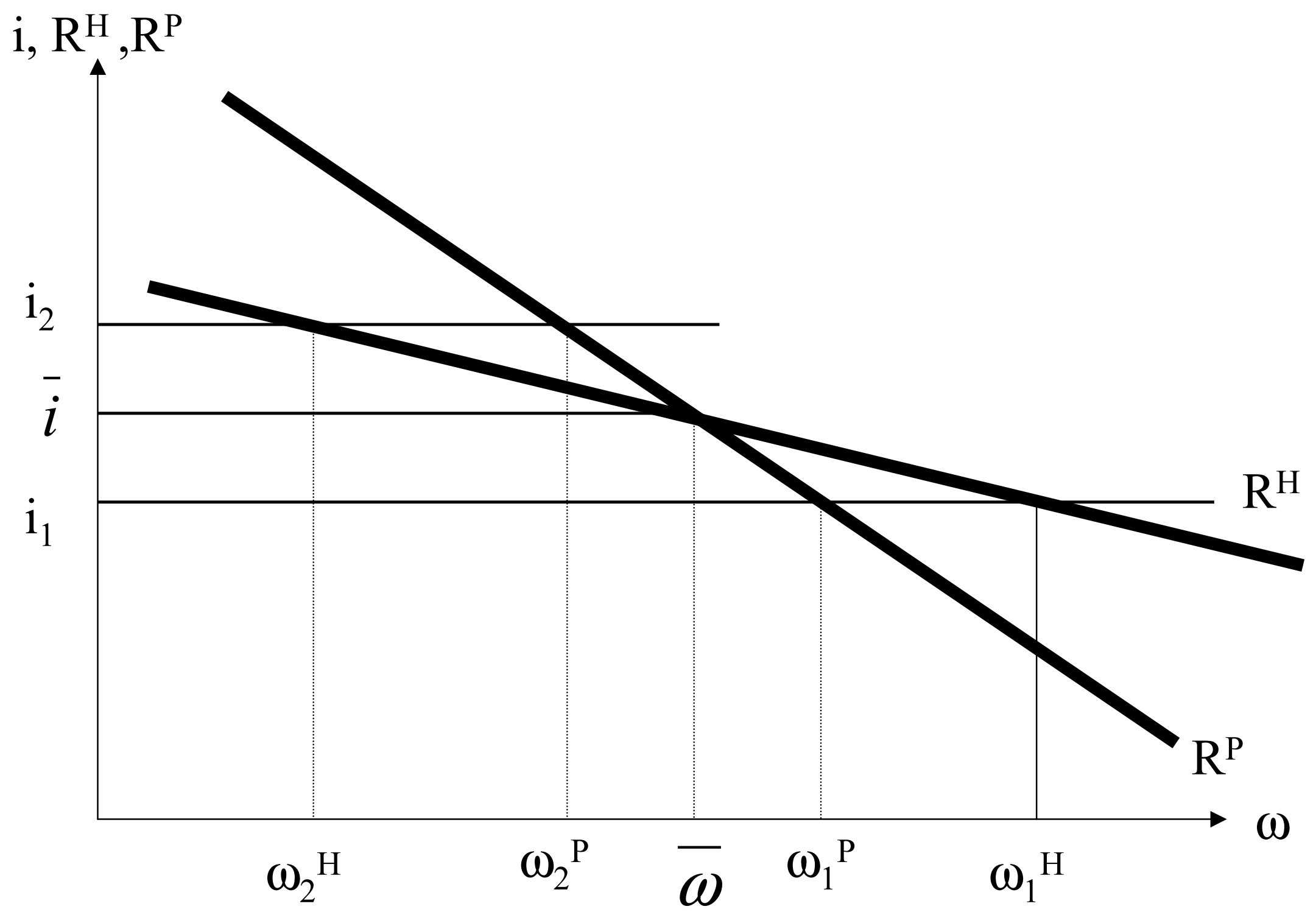

Figure 1: Determination of the ultimate ownership concentration as a function of the required investment $i$. 